\title{
DE MONJAS Y TROPOS. Música tardomedieval en un convento mallorquín ${ }^{1}$
}

\author{
Carmen Julia GutIÉRrez
}

\begin{abstract}
A late medieval musical manuscript from a nunnery at Palma de Mallorca, contains a rich repertory of hitherto unknow pieces with numerous particularities. It mixes pieces of monastic liturgy in plain chant an in mensural notation and includes monodic mensural and poliphonic pieces from the XIVth century, a good deal of tropes and some latin works with musical repetitions, quite similar to the latin laude, as well as songs to be inserted in the liturgy of the Mass which could be considered as dance music. These last pieces and some others show the strong connection of the manuscript with italian contemporary sources. Moreover, numerous indications in the manuscript from Palma regarding the interpretation of the pieces provide with very interesting information about how singing was performed at the nunneries during that period.
\end{abstract}

\section{Resumen}

Un manuscrito litúrgico-musical de un convento femenino de Palma de Mallorca escrito en época tardomedieval contiene un rico repertorio de piezas inéditas y numerosas peculiaridades. Se alternan en él piezas de la liturgia monacal escritas tanto en canto llano como en notación mensural, se incluye repertorio monódico mensural del siglo XIV, polifonía de la misma época, un gran número de tropos y algunas obras latinas con repeticiones musicales que las aproximan a las laude latinas, así como canciones insertas dentro de la liturgia de la misa que podrían considerarse de danza. Estas y otras piezas indican una fuerte relación de este manuscrito con fuentes contemporáneas italianas. Además en el manuscrito de Palma aparecen numerosas indicaciones sobre la interpretación de las piezas que nos aportan interesantes datos sobre el canto en los conventos de monjas de la época.

Este trabajo se ocupa del manuscrito s.s. conocido como Cantoral de la Concepción que se encuentra en el Museo Diocesano de Palma de Mallorca. La primera referencia a este manuscrito la hace Higini Anglès ${ }^{2}$ al citar la versión del tropo Clangat cetus del f. 9. En las pp. 298 y 302 de la misma obra Anglès se refiere a un Cantoral del siglo XV-XVI procedente de un convento de monjas que afirma haber visto en 1932 y que en $\mathrm{f}$. 84v contiene un Canto de la Sibila en catalán. Se trata, aunque no lo menciona, del mismo manuscrito. En 1956 Bruno Stäblein fotografió este libro y varios investigadores posteriores lo han utilizado para sus trabajos (vid. Thannabaur o Eifrig, citados más adelante), pero nunca se ha abordado su estudio de forma integral.

1. Al Dr. Andreas Haug mi sincero agradecimiento por compartir conmigo su sabiduría e intuiciones

2. La música a Catalunya fins al segle XIII (Barcelona: Biblioteca de Catalunya, 1935), p. 152. 
La importancia del libro radica en que contiene piezas litúrgicas escritas tanto en canto llano como en notación mensural y que incluye polifonía y repertorio monódico del siglo XIV. El gran número de tropos y las piezas inéditas que en él aparecen, además de las particularidades litúrgicas como la inserción dentro de la misa de piezas latinas escritas en notación mensural con una forma musical y textual que las aproximan a las laude latinas son otros hechos importantes. $\mathrm{Su}$ procedencia de un monasterio femenino nos aporta además interesantes datos sobre el canto en los conventos de monjas.

La descripción del manuscrito es la siguiente:

\section{Palma de Mallorca, Museu Diocesà s. s. (E-Pm)}

Manuscrito de 123 folios, de finales del siglo xIV o principios del XV, con correcciones posteriores. En la guarda está escrito: «de la Concepción». Mide $530 \times 385 \mathrm{~mm}$. Numeración moderna a lápiz. Comienza incompleto y en los márgenes izquierdos de los folios vueltos pone otra numeración en números romanos que comienza en el folio X. Faltan algunos folios. Escritura gótica a línea tendida excepto para la polifonía que va a dos columnas (ff. 52v-54r y 55r$58 v)$. Numerosas rúbricas en mallorquín. Notación cuadrada gregoriana, sobre una línea roja y otra amarilla con las otras dos líneas marcadas a punta seca. Alguna pieza está escrita en cantus fractus y otras, entre los ff. 35r y 61r, en notación mensural.

El libro procede de un monasterio femenino de agustinas, como indican las rúbricas y el tipo de oficio con nueve responsorios. Aunque en su guarda puede leerse «de la Concepción» no puede proceder del monasterio mallorquín de ese nombre, pues éste fue fundado en 1564. En Palma de Mallorca hubo otro Convento de la misma orden religiosa, las ermitañas de la orden de San Agustín: el antiguo convento de Santa Margarita, fundado en la ciudad de Palma en 1232, se trasladó en 1279 al edificio que hasta entonces ocupaban los franciscanos en la calle de Sant Miquel. En 1837 las religiosas de este convento pasaron al de La Concepción y el antiguo convento de Santa Margarita se convirtió en Hospital Militar. Así, este cantoral se encuentra ahora en el Museo Diocesano con la indicación «de la Concepción.»

El contenido del manuscrito es el siguiente:

f. 1: Comienza incompleto con el final de un Sanctus sigue un Agnus Dei y un Benedicamus Domino.

f. 1v-6v: Himnos del oficio ferial y dominical.

f. 7r: «Aqui comensa lo Santoral e primerament en les solemnitats de la Verge Maria segons se segueix: Kyrie.» Rex Virginum amator Deus.

f. 7v: Aquest seguents kyris se dient dentre octaves de la Verge Maria e a tres lissons»: Kyrie.

f. 8r: $\quad$ Gloria Spiritus et alme.

f. 9r: Sanctus Clangat cetus.

f. 10r: Agnus Dei (sin tropar).

f. 10v: Ite missa est (dos).

f. 10v: «A dobla maior»: Summe pater voces in iubilo, eleison.

f. 11r: «Axi mateix aquest son de dobla maior»: Kyrie fons bonitatis, Gloria, Sanctus, Agnus Dei y tres Ite missa est (excepto el Kyrie, todo sin tropar). 
f. 14r: «In festivitatibus sanctorum apostolorum»: Kyrie, Gloria, Sanctus, Agnus Dei e Ite missa est.

f. 16r: «A festas de dobla manor»: Kyrie, Gloria, Sanctus, Agnus Dei e Ite missa est.

f. 18r: «A tota festa de nou lissons»: Kyrie, Gloria, Sanctus, Agnus Dei e Ite missa est.

f. 20r: A tota festa de tres lissons: Kyrie, Gloria, Sanctus, Agnus Dei e Ite missa est.

f. 21v: «En la missa dels deffunts dieu aquestes»: Kyrie, Sanctus y Agnus Dei.

f. 22r: «Apres tots sancts en lo die dels defunts diu hom a la missa aquests Kyris, Sanctus e Agnus»: Kyrie, Sanctus y Agnus Dei.

f. 23v: «Assi comensan les Completes ferials de tot l'ayn. E primerament comensa la semana dient:» Iube domne benedicere. A continuación incluye las antífonas marianas Ave regina caelorum y Salve Regina.

f. 26r: $\quad \mathrm{R} /$ para la Cuaresma: In pace

f. 26v: $\quad \mathrm{A} /$ ad Nunc dimittis: Media vita in morte sumus

f. 27v: $\quad \mathrm{A} /$ ad Nunc dimittis: $O$ regem tuum Domine.

f. 28r: $\quad \mathrm{A} /$ ad Nunc dimittis: Vigilemus omnes in Christo.

f. 28v: Antífonas de Completas para todo el año litúrgico: $O$ virgo virginum quomodo (28v). Maria intacta Virgo Deum (28v). Regina caeli (29r). Alma redemptoris (29r). Ave stella matutina (29v). Ave consurgens aurora (30v) Quam pulchra es (31r). Ave regina celorum, ave domina angelorum (31v). Stella solis (32r). Regina celi laetare (33r). Virgo mater resurgentis (33v). O florens rosa (34r) Ave virgo singularis (34v)

f. 35r: «En lo die de Nadal se diu a Vespres aquesta prosa»: Laetabundus exsultet fidelis chorus. P. Alleluia. Regem regum.

f. 36r: «En los dissaptes los quales son de la festa de Nadal fins a la festa de la verege Maria de febrer se diu aquesta a la missa ans del evangeli»: Ad honorem virginis cantemus omnes.

F. 37r: «En lo iorn de pascha a les laudes e en los altres diumenges fins ascensió segui aquesta prosa a missa ans del evangeli»: Victime paschali laudes.

f. 38r: «E aquesta se diu a vesperas lo iorn de pascha»: Assunt enim festa paschalia.

f. 39r: «De pascua fins Ascensió en los disaptes a missa diu hom aquesta»: Virginis Marie laudes intonet christiani.

f. 39v: «E lo iorn de Qinquagesima el diluns vinens a vesperes aquesta»: Veni Sancte Spiritus.

f. 40v: «Aquesta prosa es dels princeps del apostols sant Pere e sant Pau»: Gaudet chorus electorum.

f. 43r: «Et aquesta es diu a cascuna festa del apostols»: Celi solem imitantes.

f. 44v: «Lo die de la circumcisio de Iesu Christo so es lo iorn de An nou a les segones vespres se diu aquesta verbeta de duas e duas cascun ves e apres lo Alleluia seguent»: Ecce puerpera genuit Hemmanuel. Al. Multifarie.

f.45v: «En les vespres segones de la festa de sant Ioha babtista se diu aquesta verbeta de duas en duas»: Ave dei dilecte babtista.

f. 47r: «En la festivitat de la ascensiò de la verge maria en lo mes de agost a les vespres segonas se diu aquesta verbeta»: Aurea nempe adest et pulchra.

f. 49r: «A cos present de alquna deffuncta deinetra offeran o anans o apres podeu dire la seguente prosa»: Kyrie eleison, Christe eleison Iesu parce ei . V/ Mater dei propera mostra.

f. 51r: Credo monódico. (Credo I).

f. 52v: Credo a 2 voces. (Credo IV), incompleto. 
f. 54v: Credo monódico. (entonación del Credo I, pero otra melodía).

f. 55r: $\quad$ Credo a 2 voces.

f. 58v: «Los seguents versos son de aquest santus los quals ia son perfetamente notats en lur lach e offici demut»: Sanctus. Osanna. Gaudeat chorus celestium.

f. 59v: Sanctus. Osanna. Verbum caro factum est.

f. 60v: Sanctus. Osanna. Ave verum corpus.

f. 62v: «Aqui comensa lo offici per adorar la creu»: Popule meus. «E duas infantonas vagen denant aquels qui aporten la creu e canten aquest versos seguents»: Agios o Theos. «E totas les sos agenollades responguen axi dienst»: Sanctus o Deus. «E assi aquels que aporten la creu acostense un pochanant ves l'alar dienst e cantant axi»: Ego quidem transvexite mare rubrum.

f. 63v: Prosa: $O$ crux frutex salvificus.

f. 66r: «E si necessari hi fera apres desta prosa cante lo ymne seguent segon ia es en psalteri notat»: Pange lingua gloriosi prelium

f. 66v: Oficio de la Virgen (con todos los $\mathrm{R} /$ en las ferias y sábados y los R/ y V/ de cuaresma).

f. 73r: «En los disaptes del advent a matinas diu hom les antifones benedicta tu ab les altres seguents ut supra e lo primer respons es aquest»: Missus est Gabriel (siguen los nueve $\mathrm{R} /$ y más para otras épocas del año, siempre el oficio de la BMV, y a continuación las antífonas.

f. 81v: «En lo dilons de la cena apres lo levament dels peus deu lo sant restament de Iesu Christe salvator nostro segons se segue assi»: Ante diem festu pasche (sigue la lectura).

f. 84v: «Lo iorn de Nadal allanovena lissó una bona cantora diu lo Iorn de iudici segons se segue assí»: Al iorn del iudici. (Canto de la Sibila).

f. 87r: «En las primas vespras ad sant angel que es dit custos»: siguen los oficios y la misa de los arcángeles.

f. 103v: «En lo vuyte iorn del mes de mayg es la festa de la revelacio o apparicio de mosseyer sant michel, a les primas vesperas»: Ant. Stitit angelus.

f. 118v: Benedicamus Domino.

f. 120r: Ave maris stella. (himno).

f. 120v: Virgo prudens et formosa. (himno).

f. 121v: Gloria in excelsis Deo («dels angelis») Gloria (de BMV).

El manuscrito es un Cantoral en el que se escriben las piezas cantadas de las fiestas más importantes tanto para los oficios como para la misa. Escribe en primer lugar 33 himnos del oficio ferial y dominical que no ofrecen ninguna particularidad destacable en sus textos — sólo seis diferentes en total- pero sí en sus melodías: 11 diferentes para estos seis textos, de las que tres son únicas y suponemos que de composición local, pues no se han podido identificar en los repertorios internacionales. ${ }^{3}$ El manuscrito ofrece más adelante insertos en sus oficios correspondientes otros 13 himnos más que contienen algunos textos inéditos, como Aeterni regis milites (f. 95r,

3. Las melodías se han cotejado con Stäblein, Bruno: Monumenta Monodica Medii Aevi I. Hymnen 1 (Kassel-Basrel: Bärenreiter, 1956) y GuTIÉrrez, Carmen Julia: Monumenta Monodica Medii Aevi X: Hymnen 2: Spanien (Kassel-Basel: Bärenreiter, en preparación). 
San Gabriel). Angelum nobis medicum salutis (f. 109v, San Rafael) o Virgo pridens et formosa (f. 120v, BMV).

No voy tratar aquí el repertorio himnódico de este libro, pero sí creo necesario mencionar que una de las características de los himnos de Pm es una constante en el manuscrito: el empleo de melodías de nueva composición. Es por ello muy probable que sean también de nueva composición otras melodías únicas o al menos que no he podido identificar. Es incluso posible la composición local de estas piezas, hecho por el momento indemostrable mientras no se estudie el repertorio contemporáneo de la isla.

Tras los himnos, el manuscrito de Palma incluye ocho ordinarios completos de la misa (ff. 7r-23r), la mayor parte de ellos con uno o más Ite missa est y en los dos primeros con varias piezas tropadas, una de ellas inédita.

Siguen los oficios de completas (ff. 23v-34v), en los que son destacables las antífonas de los ff. 28v-34v, varias de ellas rimadas y varias inéditas (Maria intacta virgo, Ave consurgens aurora, Stella solis, Virgo mater resurgentis, y Ave virgo singularis ). A continuación el manuscrito nos ofrece otra serie de piezas tropadas (ff. 35r-61r) colocadas en orden litúrgico para la misa calificadas en las rúbricas unas como «prosas» (las prosas o secuencias del Alleluia), otras como «verbetas» ${ }^{4}$ (tres prósulas del Alleluia) y otras como «versos» (tres Sanctus tropados). Intercalados en esta sección y colocados en su lugar litúrgico correspondiente aparecen cuatro Credo, (ff. 51r-58r) dos de ellos monódicos y dos polifónicos.

Más adelante el manuscrito ofrece los oficios de la Cruz, de la BMV y de los Arcángeles, así como un Canto de la Sibila en catalán.

El objeto de este trabajo es el estudio de las piezas inéditas o versiones inéditas de piezas conocidas que aparecen en este cantoral. La mayor parte de estas obras son tropos o aparecen copiadas como tal y su interés, aparte del hecho de no estar editadas y de que alguno de los tropos se ha podido relacionar con su pieza base consiste en:

- Las indicaciones que se dan en las rúbricas y signos del manuscrito, que muestran cómo eran interpretadas las piezas por las monjas.

- Algunas de las piezas están escritas con notación mensural ofreciendo versiones del repertorio litúrgico tanto monódico como polifónico del siglo XIV.

- Alguna de las piezas es una interpolación de una canción latina dentro de la liturgia monacal. El ritmo y la forma de estas canciones las aproximan a las laude latinas.

\section{Ordinario de la misa}

En el Cantoral de la Concepción (ff. 7-23) se copiaron en su momento ocho juegos completos de ordinario de la misa que incluyen en total 10 Kyrie (con ocho melodías diferentes, tres

4. «Verbeta» es el término usado en área catalana para referirse a las prósulas. 
de ellos tropados), seis Gloria (con seis melodías diferentes, uno de ellos tropado), ocho Sanctus (con siete melodías diferentes, uno de ellos tropado), ocho Agnus Dei (con cinco melodías diferentes) y nueve Ite missa est (con nueve melodías diferentes). Aunque colocados en otro lugar (ff. 51r-57v), hay que mencionar aquí los cuatro Credo, dos monódicos y dos polifónicos. Como es habitual, no hay tropos en los Credo, que sin embargo están ornamentados por medio de la polifonía y del ritmo mensural. Estas piezas son de gran interés ${ }^{5}$ debido a que una de ellas es inédita; tres de ellas presentan interesantes concordancias con otras fuentes europeas; tres de ellas están escritas con notación mensural, y aportan nuevos ejemplos de la polifonía y la monodía mensural del siglo XIV. Dentro del ordinario de la misa deben incluirse los Sanctus tropados (ff. 58v-61r), pero por sus peculiares características se comentan en un capítulo aparte.

El estudio de las melodías de estos ordinarios de la misa - en los que incluyo también los Benedicamus Domino que se encuentran más adelante en el manuscrito (f. 118v-121r) — nos aporta el dato sorprendente de que más de la mitad de las melodías de estas piezas son únicas. ${ }^{6}$ Este hecho es especialmente notable en lo que se refiere a los Ite missa est y Benedicamus, que han sido cotejados con la edición de Eifrig $^{7}$ y de la que resulta que de nueve Ite missa est, cinco tienen una melodía conocida sólo por esta fuente, mientras que de los 30 Benedicamus, nada menos que 22 presentan melodías únicas. Este mismo hecho ha sido ya mencionado respecto a los himnos del oficio.

Casi todas las piezas tropadas del ordinario son conocidas y aparecen en otras fuentes peninsulares y del resto de Europa. Sin embargo, el tropo de Kyrie Summe pater voces in iubilo, eleison es inédito.

El volumen XLVII de Analecta Hymnica ${ }^{8}$ (en adelante AH) en su número 164 nos da una versión de un tropo con este mismo incipit procedente de una fuente catalana: F-Pn n.a. 495: Tropario de Gerona, siglo XIII, f. $14 \mathrm{v}$, escrito por una mano posterior. También lo he podido ver en E-TORc 135: Tropario de Tortosa, siglo XIII, f. 4r, E-Bc 911: Tropario de Gerona, siglo Xv, f. 20v y E-Gm: Tropario de Gerona, siglo XVI, p. 570. Sin embargo, tanto en la fuente que edita AH como en las que yo he cotejado, aunque la melodía es la misma, sólo coincide el texto del primer verso con la versión de $\mathrm{Pm}$.

La melodía de este Kyrie es bien conocida y aparece con el n ${ }^{\circ} 26$ del catalogo de Melnicki (de F-Pn 1134: Cantatorium de St. Martial, s. XI, f. 2v —en donde aparece en una adición poste-

5. Sobre ellas hemos realizado otro trabajo de próxima aparición.

6. Las melodías del ordinario de la misa han sido cotejadas con las ediciones de Bosse, Detlev: Untersuchung einstimmiger mittelalterlicher Melodien $z u$ Gloria in excelsis Deo (Inaugural Dissertation der Philosophischen Fakultät der Friedrich AleXander Universität zu Erlangen Nürnberg, 1954); MELNICKI, Margareta: Das einstimmige Kyrie des lateinischen Mittelalter (Idem, 1954); SCHILDBACH, Martin: Das einstimmige Agnus Dei und seine handschriftliche Überlieferung vom 10. bis zum 16. Jahrhundert (Idem, 1967); Thannabaur, Peter Josef: Das einstimmige Sanctus der römischen Messe in der Handschriften Überlieferung des 11. bis 16. Jahrhunderts. (München: Verlegt bei Walter Ricke, 1962); MiazGA, Tadeusz: Die Melodien des einstimmigen Credo der Römisch-katholischen lateinischen Kirche. (Graz: Akademische Druck u. Verlagsanstalt, 1976) preparación)

7. EIfRIG, William F.: Edición integral de las melodías de Ite missa est (Monumenta Monodica Medii Aevi Band XIX, en

8. Blume, Clemens und Dreves, Guido Maria: Analecta Hymnica Medii Aevi XLVII: Tropi Graduales. I. Tropen zum Ordinarium Missae. (Leipzig, 1905). 
rior al códice- y F-Pn 5247: Sequentiarium de Saint Robert [Casa Dei], s. XIV, f. 147v). Melnicki con esta melodía cita únicamente el tropo Pater summe qui (AH $47 \mathrm{n}^{\circ} 71$ ), tomado de fuentes del siglo XIV. Esto indica que tanto esta melodía como los dos tropos publicados y relacionados con ella, Pater summe qui y Summe Pater voces, son conocidos en ámbito francés relativamente tardío (s. XIII) mientras el tercer tropo que sobre la misma melodía escribe Pm es inédito.

Pm f. 10v. Misas de doble mayor: Kyrie:
1. Summe, Pater, voces in iubilo,
2. Christe, mundi vera redemptio, eleison. Kyrie eleison. Kyrie eleison.
3. Voces nostras exaudi caelitus, eleison. Kyrie eleison. Christe eleison.

\section{Prosas y prósulas}

Las piezas de los ff. 35r-66v según las definiciones del propio cantoral son:

- 10 piezas calificadas como «prosas» (secuencias) por el propio manuscrito.

-3 piezas calificadas como «verbetas», que son tres prósulas del Alleluia.

Casi todas las prosas son son conocidas y editadas por AH a excepción de Ad honorem virginis, y Kyrie. Iesu parce ei. Sin embargo algunas de ellas ofrecen importantes variantes respecto a la edición AH. Las verbetas Ecce puerpera y Ave Dei dilecte son conocidas a través de otras versiones que difieren notablemente de Pm.

$\begin{array}{ll}35 \mathrm{r} & \text { Laetabundus /regem regum (prosa) } \\ 36 \mathrm{r} & \text { Ad honorem virginis (prosa) } \\ 37 \mathrm{r} & \text { Victimae paschali laudes (prosa) } \\ 38 \mathrm{r} & \text { Assunt enim festa paschalia (prosa) } \\ 39 \mathrm{r} & \text { Virgini Mariae laudes (prosa) } \\ 39 \mathrm{v} & \text { Veni Sancte Spiritus (prosa) } \\ 40 \mathrm{v} & \text { Gaudet chorus electorum (prosa) } \\ 43 \mathrm{r} & \text { Caeli solem imitantes (prosa) } \\ 44 \mathrm{r} & \text { Ecce puerpera (verbeta) } \\ 45 \mathrm{r} & \text { Ave Dei dilecte Babtiste (verbeta) } \\ 47 \mathrm{r} & \text { Aurea nempe adest et pulchra (verbeta) } \\ 49 \mathrm{r} & \text { Kyrie. Iesu parce ei. Mater Dei propera (prosa) } \\ 63 \mathrm{v} & \text { O crux frutex salvificus (prosa) }\end{array}$

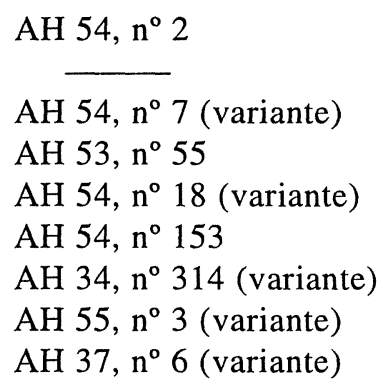

En muchas piezas está señalada determinada alternancia de intérpretes: con el signo P/, que indica que esa sección debe ser cantada por el coro o por dos monjas frente al resto de la pieza, señalada $\mathrm{v} /$, que cantan otras dos monjas solistas. La alternancia se indica en las rúbricas: «... se diu aquesta verbeta de duas en duas cascun vez» (f. $44 \mathrm{v}$ ), o «... se diu aquesta verbeta de duas en duas» (f. 45), o bien «E duas infantonas vaguen denant aquels qui aporten la creu e can- 
tent aquest versos seguents» (f. 62v). Las consuetas y las rúbricas de otras fuentes contemporáneas de área catalana confirman que en los monasterios había una schola de cuatro cantores. ${ }^{9}$

Estas indicaciones de alternancia aparecen en Laetabundus, Ad honorem, Assunt enim, Iesu parce ei, Ecce puerpera, Ave Dei y Aurea nempe. Las solistas (V/) interpretan el texto de las prosas y las partes tropadas en las prósulas mientras que el resto repite en las prosas una breve melodía para el último verso y en las prósulas la melodía tropada interpretada con una vocalización sobre la letra correspondiente. Un caso diferente es Iesu parce ei, una pieza en la que las dos secciones del coro alternan en la interpretación de los versos y el estribillo «Iesu parce ei».

En efecto, Iesu parce ei es una obra con estribillo, pero es de destacar en Pm la existencia de varias obras con pequeñas repeticiones musicales de una breve melodía para el último verso de cada una de las estrofas que no siempre es igual, sino que ocasionalmente realiza ligeras variaciones. Las repeticiones de frases musicales no son por supuesto ajenas a las composiciones medievales, ni tampoco el uso de estribillos (véase los conductus), sin embargo, en la época de la que nos estamos ocupando, las únicas piezas en las que se emplea este tipo de construcción musical con texto en latín son las laude latinas, piezas de gran arraigo y popularidad en Italia. Esto y otros hechos, como las concordancias de las fuentes (especialmente en los Credo) y la pervivencia de algunos textos de laude (los denominados «versos» de Sanctus) en Pm nos lleva a suponer una fuerte relación de este manuscrito con Italia, lo cual es muy plausible dada la relación entre la Corona de Aragón y éste país en los siglos XIV y XV.

Las piezas en las que se pueden ver estas repeticiones son: Gaudet chorus electorum, Caeli solem imitantes, Iesu parce ei (además con estribillo), Gaudeat chorus celestium, Verbum caro factum est (con estribillo) y Ave verum corpus. Si tenemos en cuenta que entre estas seis obras se incluyen cuatro de las que suponemos tienen una melodía inédita y que todas estas «riprese» tienen una gran semejanza melódica entre sí, podemos sugerir una posible composición local como conjunto de estas piezas, posiblemente inspirándose en algún caso en repertorios venidos de Italia y transmitidos a las agustinas de Palma por medio de alguna fraternidad de laudesi o quizá por alguna relación monástica que por el momento desconocemos.

\section{Laetabundus... / regem - Ad honorem virginis}

Respectivamente son una Prosa de Navidad y Prosa para los sábados desde Navidad hasta la fiesta de febrero de la BMV. La segunda de ellas es inédita, se trata de un contrafactum de la conocida Laetabundus, que aparece en primer lugar, escrita en notación mensural (adición posterior) y con una indicación de alternancia (P/), entre las cantoras según la cual, el coro debe repetir la melodía del último y breve verso de cada estrofa. Exactamente la misma indicación de alternancia y para el mismo verso final se encuentra en el contrafactum Ad honorem virginis. La similitud entre Laetabundus y Ad honorem se puede ver:

9. E-Bc 276 (Consueta de Tarragona s. XIV), f. 69v: «... Ad vesperos super salmos antiphone de laudibus cum psalmis vespertinalibus beate Marie, verbeta aurea nempe cum alleluia veni de libano, et cantetur a iiii cantoribus et in se ipsa verbeta finiatur». E- Bc 911 (Tropario de Gerona, s. Xv), f. 47v: «In missa de luce hic Alleluia incipitur ab officiatoribus et pneuma dicat a toto choro, sed versus dicantur quatuor clericis divise de doubus in duobus.» 
- En los esquemas de composición textual y rima: doce estrofas pareadas que riman dos a dos a a a b, siendo la rima «b» en ambas secuencias sobre la letra «a».

- En los esquemas métricos de la composición, pues se repiten casi siempre los mismos esquemas de pies troqueos en las estrofas con algunas excepciones, siendo la más notable la terminación paroxítona de algunos de los primeros versos en Ad honorem (1b: finis; 4a: Galilea; 6a: pia; 6b: natum) que no se da en Laetabundus.

- En la estructuración temática. En un trabajo de 1984, ${ }^{10}$ Wulf Arlt realiza una interesante disección la secuencia Laetabundus en la que muestra como la composición del texto se estructura en tres partes: I: estrofas $1 \mathrm{a}$ y $1 \mathrm{~b}$, exhortación. II: estrofas $2 \mathrm{a}$ y $2 \mathrm{~b}, 3 \mathrm{a}$ y $3 \mathrm{~b}, 4$ a y $3 \mathrm{~b}$ : narran el hecho que se festeja. III: estrofas $5 \mathrm{a}$ y $5 \mathrm{~b}$ y $6 \mathrm{a}$ y $6 \mathrm{~b}$ : applicatio. La misma estructuración puede verse en Ad honoris.

- La melodía. A pesar de las numerosas versiones de Laetabundus que se conocen - las principales de las cuales compara Arlt en el citado trabajo-, la versión de Pm se acerca notablemente a las más antiguas colacionadas por Arlt, especialmente a la del Tropario normandosiciliano E-Mn 289, lo cual, según la tesis de Arlt, demostraría la temprana trasmisión de la secuencia en un área «central» respecto al origen de la misma. ${ }^{11}$

Pm, f. 36r: Prosa para los sábados desde Navidad a la fiesta de febrero de la BMV:

1a. Ad honorem virginis cantemus omnis voce una.

2a. Salutata credidit et credendo concepit Nunque tacta.

3a. Que dum magi requirunt puerum inveniunt duce stella.

4a. Ascendensque ethera mirante Galilea nube clara.

5a. Gaudent omnes angeli latetur arcangeli genitrice Domini Caelo sumpta.

6a. Ergo mater pia esto propicia husque concinunt Hec gaudia 1b. Congaudentes de finis septem gaudiis que sunt ista

2b. Virga sicca floruit Iesse Virgo genuit incorrupta.

3b. Qui pro nobis mortuum surrexit iam triduum morte victa.

4b. Missit suis natibus flamme Sancti Spiritus Die dena.

5b. His eternis gaudiis exsultas cum superis mater dei et hominis O Maria

6b. Roga tuum natum tenens sic placatum ut qui hec credunt. Det gloriam.

Amen.

10. ARLt, Wulf: «Secuence and "Neues Lied"» en La Sequenza medievale. Atti del Convegno Internazionale Milano 7-8 Aprile 1984 (Lucca: Libreria Musicale Italiana, 1992): 3-18.

11. ARLT, Wulf: op. cit. p. 16. 


\section{Victimae paschali laudes - Virgini Mariae laudes}

Prosa de Pascua y Prosa para los sábados desde Pascua a la Ascensión.

Otro caso, en esta ocasión bien conocido, de contrafactum entre dos secuencias. Nos interesa destacar aquí que en ambas el texto es el editado en $\mathrm{AH}$, pero con una particularidad como es intercalar la frase «Dic nobis Maria quid vidisti in via» tres veces a modo de estribillo (tachado posteriormente, al igual que la estrofa «Credendum est magis soli»), con lo que rompe la estructuración musical de la secuencia, pero repite la pregunta a María, que cantaría el otro semicoro. Este mismo esquema de repeticiones e incoherencia con la forma musical A BB CC... se da en el contrafactum de este texto Virgini Marie laudes y en los dos casos la música y el texto está copiado completo, por lo que no cabe duda de que se cantaba así, hecho que no es desconocido, pues hay ejemplos de secuencias con estribillo intercalado desde época temprana. ${ }^{12}$

A continuación se puede leer cómo el manuscrito escribe tanto una como otra secuencia. En letras minúsculas hemos desglosado las semifrases musicales de cada frase textual y las mayúsculas indican la frase de cada estrofa que en efecto reflejan habitualmente la estructura típica de la secuencia A BB CC DD...

\section{Texto}

1. Victimae Paschali laudes inmolent christiani

2a. Agnus redemit oves Christus innocens patri reconciliavit peccatorum. B

2b. Mors et vita duello conflixere mirando dux vite mortuus regnat vivus. B

3a. Dic nobis Maria, quid vidisti in via? Sepulchum Christi viventis, et gloriam vidi resurgentis.

Dic nobis Maria, quid vidisti in via?

3b. Angelicos testes, sudarium et vestes. Dic nobis Maria, quid vidisti in via?

Surrexit Christus spes mea, precedet suos in Galilea

4a. Credendum est magis soli marie veraci quem iudeorum turbe fallaci.

4b. Scimus Christus surrexisse a mortuis vere tu nobis victor rex miserere

\section{semifrase frase}

A

$\begin{array}{ll}\text { B } & \\ \text { B } & \\ \text { a } & \text { C } \\ \text { b } & \\ \text { a } & \text { C" } \\ \text { a } & \\ \text { a } & \text { C } \\ \text { b } & \\ \text { D } & \\ \text { D } & \end{array}$

Pm f. 39r: Prosa para los sábados desde pascua a la Ascensión (AH 54, n 18 la edita con grandes variantes):

\section{Virgini Mariae laudes} intonent christiani.

2a. Eva tristis abstulit, sed Maria protulit natum, qui redemit peccatores.

3a. Dic nobis Maria, virgo clemens et pia Quomodo facta es genitrix, cum tu sis plasma de te nascentis? (Dic nobis Maria, Virgo clemens et pia.) 2b. Mors et vita modulo convenere mirando Mariae filius regnat Deus.

3b. Angelus est testis, ad me missus caelestis; (Dic nobis Maria, Virgo clemens et pia.) Natus est ex me spes mea, sed incredula manet Judea.

12. KRUCKEMBERG, Lori: The Sequenze from 1050-1150: Study of a Genre in Change (Diss. Univ. of Iowa, Iowa City, 1997) 
4a. Credendum est magis soli Gabrieli fortiex qui a judeorum ravae cohorti. 4b. Scimus Christum processione

Maria matre tu nobis Christe rex miserere.

Amen.

\section{Gaudeat chorus electorum}

Prosa para la fiesta de los apóstoles San Pedro y San Pablo.

Escrita en notación mensural. Editada en AH 34 n³ 314, también de fuentes de procedencia catalana (E-VI 105, f. 73v, ${ }^{13}$ E-Bc 911 , f. 115 r y E-TORc 135 , f. $75 v$ ), pero con variantes textuales y de organización de las últimas estrofas. Es evidente que el o la copista del manuscrito Pm no conocía esta secuencia, pues olvida copiar una estrofa, que añade posteriormente en el margen inferior, y este olvido hace que la repetición melódica dos a dos se rompa, pues la estrofa en cuestión (10a. Mentiti Deo) queda sin su pareja melódica. La versión correcta de organización estrófica sería la que dan las otras tres fuentes catalanas, dejando libre la primera estrofa: A BB CC DD... La melodía de Pm no es la misma que la de las otras fuentes, con una variante notable en la organización de las estrofas 13 y 14, en las que escribe un verso más, por lo que posiblemente recoga una tradición diferente a la catalana y nueva para el/la copista.

Pm, f. 40v: Prosa para la fiesta de los apóstoles San Pedro y San Pablo.
1a. Gaudet chorus electorum ad festivam beatorum Petri, Pauli gloriam.
1b. Quos doctores et pastores ordinavit et sacravit Christus in ecclesiam,
2a. Qui dignatus est vocare dum transiret iuxta mare, Petrum ad hanc gratiam.
2b. Rebus suis iam exutus Christum pauper est secutus spretis, quae possederat.
3a. Vidit Christum, verbum Dei, claves caeli dantur ei, per quas caelos reserat.
3b. Christo prosternitur Saulus in quem persequitur Christus cuius membra laniat.
4a. Iustum lapidantibus favit, quorum vestibus datur, ut custodiat.
5a. De lupo factus est agnus et de Saulo doctor magnus viri iusti precibus.
6a. Perituri sunt ligandi sunt solvendi coronandi, sed secundum merita per doctrinam veritatis traxit Dionysium.
7a. Ad culturam deitatis
4b. Stephanus, dum lapidatur, tunc pro Saulo deprecatur Iesum flexis genibus.
5b. Unus ligat atque solvit melius, quam mens revolvit, potestate tradita.
6b. Alter vero, vas honoris, sanitas damnat orroris docens evangelium.
7b. Petrus in excessum mentis vas submissum ligamentis in figura gentium.
8a. Videns vidit et agnovit, quod Deus ad fidem movit gentilem Cornelium.
8b. Caelos tonat, unde manat fons salutis, lux virtutis, Dei sapientiam.

13. Vic, Museu Episcopal, ms. 105: Tropario prosario siglo XII. 
9a. Ad arcana verba sana Paulus audit, quorum claudit signata mysteria.

(10a. Mentiti Deo connatur et per Petrum morti dantur, res est admirabilis.)

11a. Paulus ante persecutor, nunc est sponsae Christi tutor, cuius sanctus est adiutor spiritus scientiae.

12a. Primatum sanctae cohortis Petrus habet fidem fortis, pro cuius amore mortis non timet pericula.

13a. Paulus ense decollatur, Petrus cruce coronatur sic simul in gloria.

14a. Istos fratres, honoremus, ut excusent, quod timemus, nostra prava opera. 9b. Ananias et Saphira, super quos ascendit ira irremediabilis.

11b. Fidem Christi dum revelat, cuius sponsa caste celat narrat hoc, quod ante celat, filiis ecclesiae

12b. Porta Syon exaltata super Petrum est fundata, super omnia amata Iacob tabernacula

13b. Hi gubernant urbem lucis, cuius porta signum crucis, duo luminaria.

14b. Per quos Roma gloriatur, et romana gobernatur Per orbem ecclesia.

Amen.

\section{Caeli solem imitantes}

Prosa para la fiesta de los Santos Apóstoles.

Escrita en notación mensural. Las variantes que ofrece esta versión respecto a la editada por AH $55 \mathrm{n}^{\circ} 3$ son numerosas, sobre todo en lo que respecta a la ordenación y número de estrofas. Casi todas aparecen en $\mathrm{AH}$, pero procedentes de diversas fuentes.

Pm f. 43r: Prosa para la fiesta de los Santos Apóstoles (AH 55, n 3, en parte).

1a. Caeli solem imitantes, in occasu triumphantes ortum solis afferunt.

2a. Petrum, Paulum et Andream per Neronem, per Aegeam Roma, Patras perimunt.

3a. Iuda surgit in Mathiam, dum ostendit eis viam caelestis praeconii.

4a. Thomam Indi, Iudam Persae Simonemque, sic diverse caeli caelos penetrant.

5a. Iohannes est segregatus, ab Epheso, est translatus, ad Christi connubia. 1b. Ortum solis et occasum, quorum omnes ita casum fines terrae referunt.

2b. Herodes gens galilea Iacobis et in Iudea binis vitam adimunt.

3b. Cyprus surgit in doctorem Barnabam dum eis rorem stillat evangelii.

4b. Sic ascendunt caeli caelos Ubi Christo fundunt melos nobis vitam impetrant.

5b. Mari trucidant Matheum et Indi Bartholomeum et Philiphum Scytia. 

6a. Marcus, Petrum imitatus, protopraesul inmolatus est in Alexandria.
6b. Lucas, Pauli comes fidus, post probatum duplex sidus dormit in Bithinia.
7a. His patronis vitae donis Christe nos accumula.
7b. Ut queamus, quod speramus cernere in gloria.

Amen.

\section{Ecce puerpera genuit Hemmanuel. Al. Multifarie.}

Prósula para la fiesta de la Circuncisión («verbeta» dice el manuscrito).

AH $37 n^{\circ} 6$ da la versión completa de este texto que aquí aparece abreviado en tres estrofas respecto a la versión de $\mathrm{AH}$, que la cataloga como secuencia, y como tal es bastante conocida en numerosas fuentes de relativa antigüedad. Esta es la primera de las tres «verbetas», así denominadas por el manuscrito, que se cantan - en los tres casos - relacionadas con un Alleluia $\mathrm{y}$ «de duas en duas cascun vez» como inican las rúbricas. Estas tres verbetas se encuentran también en otras fuentes conservadas en la catedral de Palma de Mallorca (manuscritos 24*, 29* y $30 *)$, lo cual corrobora nuestra suposición de un repertorio local. ${ }^{14}$

Ecce puerpera es una prosula estructurada en una serie de estrofas pareadas con diferente número de sílabas y una última suelta (señaladas $\mathrm{V} /$ ) que llevan la misma melodía cada dos y acaban con un Pneuma (indicado $\mathrm{P} /$ ) que consiste en una vocalización sobre la última vocal del texto de cada verso (a, o, e). Al final de la pieza se escribe el Alleluia Multifarie con su verso completo y con la indicación P/ para la última palabra («suo»), donde se ve de nuevo la alternancia constante en toda la pieza.

Al mantenerse la interpretación del Alleluia que da origen a la pieza tropada, como sucede en los tres casos que aquí comentamos, se tiene siempre presente el origen de la obra, que no se independiza de la pieza base.

La melodía, repetida de dos en dos estrofas - pero adaptando cuidadosamente en cada ocasión los acentos de las palabras a la agrupación neumática-, procede del Al. Multifarie. Otra versión de esta misma verbeta aparece en E-Bc $911 \mathrm{f}$. 48r, esta fuente incluye el Alleluia antes de la prosa, pero no el V/ Multifarie. También se puede ver en Pc 29*, 123v y Pc 30*, 195 (Palma de Mallorca: Archivo Catedral).

Pm f. 44v: Verbeta (Prósula) para la fiesta de la Circuncisión (AH 37, n 6).

1a. Ecce puerpera genuit Hemanuel regem in secla. P/. A.

1b. Nobis det ut omnia, quae sunt patris et sua praemia aeterna. P/. A.

2a. Pastores erant proximis in paschua. $\mathrm{P} /$. A.

2b. Bethleem ad urbem noctis sub silencio. P/. O.

3a. Claritas Dei cinxit illos fulgida. P/. A.

3b. Angelus inquint nolite metuere. P/. E.

4. Gloria regi nato laus et potestas per cuncta secula. P/. A.

14. Esta información se la debo al profesor Marius Bernadó que ha consultado directamente algunos de los cantorales de la catedral de Palma. 


\section{CARMEn Julia GutiÉRrez}

Alleluia. Multifarie olim Deus loquens patribus in prophetis novissime diebus istis locutus est nobis in filio $\mathrm{P} /$ suo.

\section{Ave Dei dilecte baptista. (Alleluia. Erat lucerna)}

Prósula para la fiesta de San Juan Bautista («verbeta» dice el manuscrito).

Otra versión diferente de esta prósula está editada por Marcusson ${ }^{15}$ p. $51, \mathrm{n}^{\circ} 24$, tomada de F-Pn 903. Bonastre en su obra sobre las verbetas en Cataluña ${ }^{16}$ transcribe una versión de la melodía de Ave Dei dilecte y de Erat Iohannes, que considera como dos verbetas diferentes a pesar de que ambas aparecen seguidas la una de la otra en todas las fuentes y de que observa y comenta la estrecha relación que existe entre ambas: «La present verbeta (Ave Dei) deu el seu origen a 1'Alleluia de la missa de la diada; el versicle d'aquest alleluia (Erat lucérna), dona lloc a la verbeta Erat Iohannes babtista lucerna, que amb l'anterior forma un conjunt temàtic molt interessant.» ${ }^{17}$

El texto comprende un exordium ${ }^{18}$ (desde «Ave Dei» hasta «... abluens cuncta», frases todas ellas continuadas por el melisma original sobre la vocal «a») y una intercalatio ${ }^{19}$ (desde «Erat Iohannes») y tuvo gran éxito en el area de influencia de Vic, donde aparece desde el siglo XII al XV. En su obra citada, Bonastre ha localizado esta verbeta en las siguientes fuentes: Bc M. 1805 (Gradual de Encamp s. XII), f. 125; Bc 276 (Consueta de Tarragona s. XIV), f. 63v; Vic V. 3 (Gradual s. XII), f. 2; Vi VI. 28 (Responsorial s. XIV), f. 1; Vi 85 (Breviarium a. 1398), f. 43v; Vi 107 (Gradual s. Xv), f. 63. Eva Castro ${ }^{20}$ añade a estas fuentes Vi 134, f. 30. Según Bernadò, también está en Pc 29*, f. 127. Fuera de esta zona sólo se conoce en el tropario F-Pn 903.

La estructura métrica irregular de esta verbeta, como de la siguiente, confirma su antigüedad y su relación con la melodía del Alleluia. La interpretación más plausible de este tipo de piezas es alternando tropo y melisma original, sin embargo, es también posible realizar ambas de forma simultánea (una sección del coro interpretaría el melisma y otra el texto). En los casos que nos ocupan, esta segunda posibilidad no me parece apropiada, puesto que en la verbeta Ave Dei, la identidad entre ambas melodías - base y tropo melógeno - se rompe a partir de «Desudando in toto» / «Qui viam» con varias notas que producen fuertes disonancias en el caso de sonar de modo simultáneo. Por otra parte, la disposición de la escritura en el manuscrito no es la adecuada para interpretar a la vez ambas partes (y sí lo es en las piezas polifónicas del mismo manuscrito).

Respecto al origen de la melodía de esta verbeta, se trata del Alleluia Erat lucerna, en la versión que ofrece Schlager I p. 166 y p. $565,^{21}$ versión que procede del manuscrito B-Br II 3823 ,

15. Marcusson, Olof: Corpus Troporum II: Prosules de la messe 1: Tropes de l'Alleluia (Stockholm: Almqvist \& Wiksell International, 1976)

16. BonASTRE, Francesc: Estudis sobre la verbeta. (Tarragona: Diputació Provincial, 1982): pp. 248-250

17. BONASTRE: op. cit., p. 247.

18. Se denomina así el texto de las prosulas unidas a melismas desarrollados sobre el vocablo «alleluia», sobre todo sobre la «a» final. (MARCUSSON, op. cit. p. 14).

19. Composición formada sobre los melismas del versículo. (MARCusson, op. cit. p. 14).

20. Castro, Eva: Tropos y troparios hispánicos (Universidad de Santiago de Compostela: Servicio de Publicaciones e intercambio científico, 1991) p. 105.

21. SCHLAGER, Karlheinz: Alleluia Melodien I. (bis 1100). Monumenta Monodica Medii Aevi Band VII (Kassel - Basel: Bärenreiter, 1968) 
f. $99 \mathrm{v},{ }^{22}$ aunque también es ampliamente conocida por fuentes francesas con otras versiones melódicas.

Pm f. 45v: Verbeta (Prósula del Al. Erat lucerna) para la fiesta de San Juan Bautista. (El Alleluia no aparece en el manuscrito)

(Alleluia. V/. Erat lucerna ardens et lucens ante Dominum Iohannes Baptista qui viam Domino praeparavit in eremo.)

(V/) Ave dei dicelte Babtista. P/ Alleluia.

V/ Tu es factus vox hec salutaria. P/ A.

V/. Monita promens ita parate viam rectam, P/ A.

V/ Quia salus astat abluens cuncta. P/A.

V/. Erat Iohannes babtista lucerna

V/ Erat lucerna.

V/. Ardens ac praefulgens et rectum sermonem semper pandens.

V/ Ardens et lucens.

V/ Hac aula precelsa robusta ferentem nullus maior Iohanne Domini karismate repletus manensque in evum.

V/ Ante Dominum.

V/ Desudando in toto spacio mundi perornat hanc divinam semitam de superno flamine affatus.

V/ Qui viam Domino praeparat.

V/ Hanc suam hanc certam secum portavit in aethereo regno. P/ A...

V/ Avit in heremo.

V/ In quo exemplo vitam ferre studeto.

V/ Cum quibus vultu leto iocundemur in evo.

V/ Ille nos ducat structo a Deo.

\section{Aurea nempe adest et pulchra (Alleluia. Veni sponsa Christi).}

Prósula del Alleluia para la ascensión de la BMV («verbeta» dice el manuscrito).

Marcusson cita este incipit, pero refiriéndose a otro tropo diferente sin relación con éste. Bonastre incluye en su edición el texto de esta verbeta procedente de las fuentes Bc 276 (Consueta de Tarragona s. XIV), f. 69v y Tc s.n. (Breviario de Pere d'Urrea, 1498). ${ }^{23}$ En ninguno de los manuscritos se conserva la música, de ahí la importancia de la fuente mallorquina, que sí la escribe. En ambas fuentes, el texto —idéntico - es mucho más breve que en Pm. Aparece también en Pc 24*, f. 135 y Pc 29*, f. 128v. Bonastre supone que el origen de esta prósula puede ser el Alleluia Veni de Libano, como dice la consueta de Tarragona: «... Ad vesperos super salmos antiphone de laudibus cum psalmis vespertinalibus beate Mariae, verbeta aurea nempe cum alleluia Veni de Libano, et cantetur a iiij cantoribus et in se ipsa verbeta finiatur» (op. cit. p. 171), sin embargo ese Alleluia no se conoce con ese nombre en los repertorios. El Alleluia que da ori-

22. Bruxelles, Bibliothèque Royal Albert prèmier, ms. II 3823.

23. Bonastre: op. cit. p. 171. 
gen a esta verbeta es Veni sponsa Christi, en Schlager $\mathrm{I}^{24}$ pp. 520-524 y 559 (nº 12 del catálogo temático) con cuatro melodías diferentes de fuentes francesas e italianas en el repertorio anterior a 1100. La versión de Pm se corresponde sobre todo con la melodía de la página 520, procedente de GB-Lbl Harl. 4951, f. $285 v^{25}$

Como en el caso anterior, la pieza consta de un exordio y una intercalatio (desde «Veni de vertice») y se puede ver la repetición de las frases melismáticas originales tras las frases tropadas, aunque, como en Ave Dei, la repetición no es siempre exacta.

Pm f. 47r: Verbeta (Prósula) para la fiesta de la Ascensión. (El Alleluia no aparece en el manuscrito):

(Alleluia. V/. Veni sponsa Christi, accipe coronam quam tibi Dominus praeparavit in aeternum.)

Aurea nempe adest et pulchra. P/ Alleluia.

Atque cunctis veneranda eupre pia. P/ A.

In qua virginitatis predicatur illibata. $\mathrm{P} / \mathrm{A}$.

Carnem quoque assumpsit dominus ex virginis utero. $\mathrm{P} / \mathrm{O}$.

Quam obtulit benigne propter nostram veniam. P/ A.

In ara crucis morte mortem necans. P/ A.

Claustra hebrei destruxit orrida. P/ A.

Ut surgens sedet patris ad dexteram. P/. A

Veni de vertice libani sponsa et cruore empta Christi. P/ Veni

Accipe coronam fulvidis preparatam ligustris. P/. Is

Haec non gemulis redimita opido pulchris. P/ Is.

Cuius scema fine finis meta et absque ullo termino. P/ O.

Hanc omnis sanctis cadentes polorum captamque coronam. P/. Quam.

Quam fulgidam tibi Dominus et salvator tuus inclitus. P/ Us.

Preparans donare per secla decretum.

Alleluia.

\section{Iesu parce ei}

Prosa ante el cuerpo presente de una hermana difunta.

Las piezas tropadas en el manuscrtito Pm se colocan seguidas y en orden litúrgico, de manera que tras las prosas coloca las «verbetas» (prósulas del Alleluia) y a continuación los «versos» (tropos del Sanctus). Así, la pieza que nos ocupa, Iesu parce ei, se encuentra justo entre las verbetas y los versos, esto es, entre el Alleluia y el Sanctus, con la calificación de prosa, que la une más bien con el primer bloque. Por otra parte hay que resaltar que esta obra aparece relacionada con un Kyrie que la precede y en cuya melodía se basa. Este Kyrie no es ninguno de los que se escriben en el principio del manuscrito y tampoco lo he localizado en el catálogo de Melnicki.

24. SCHLAGER, Karlheinz: op.cit.

25. London: British Library, Ms. Harl. 4951: Gradual de Toulouse, siglo XI-XII. 
La prosa consta de doce estrofas relacionadas de dos en dos por la misma melodía (1a1b$6 \mathrm{ab}$ ) y una última estrofa suelta (7). Entre todas ellas se va intercalando el estribillo «Iesu parce ei». Se trata de una prosa rítmica de tipo victorino en la que todas las estrofas utilizan la misma rima textual (aab). Su melodía no se ha localizado en el catálogo melódico de «timbres» de Pierre Aubry. ${ }^{26}$

Está indicada en el manuscrito una alternancia entre semicoros que cantan uno de ellos el estribillo y el otro los versos de la prosa. La melodía se basa en contínuas variaciones de un breve esquema melódico (Iesu parce ei) que se transporta o se repite con ligeras alteraciones. Otro motivo generador es el intervalo de $3^{\mathrm{a}} \mathrm{m}$ descendente. En todas las estrofas el último de los versos emplea una melodía muy relacionada con el estribillo. En este sentido, esta pieza es similar a las que siguen, piezas con repeticiones musicales que las asemejan a las laude latinas. Piero Damilano en su artículo sobre la lauda polifónica ${ }^{27}$ afirma que se conoce el caso de algunas prosas que se interpretaban con un estribillo en momentos especiales de la liturgia, y pone el ejemplo de $O$ crux frutex salvificus, precisamente otra de las secuencias que aparecen en Pm. En Italia, esas piezas se denominaban «laude».

Palma, f. 49r: Prosa ante el cuerpo presente de una hermana difunta.

Kyrie eleyson. Christe eleyson.

Iesu parce ei. Iesu parce ei. Iesu parce ei.

1a. Mater Dei propera

mostra nato pectora

ut istius scelera

iam relaxet gratis.

Iesu parce ei.

2a. Angeli succurrite $a b$ hoste deffendite et hanc vobis ducite in conspectu Dei. Iesu parce ei.

3a. Sancte Petre subuem resoluto homini ut in domo Domini ista adducatur. Iesu parce ei.

4a. Sancti Petri martyris precibus et meritis parce Christe miseris tua pietate Iesu parce ei. 1b. O regina gracie placa regem gloriae ut defuncta hodie iungat cum beatis. Iesu parce ei.

2b. Patriarchae caelitus subuente protinus ut placetur dominus miserendo ei. Iesu parce ei.

3b. Martyrum exercitus exorate quesumus ne tormentis dedita nimis molestetur. Iesu parce ei.

4b. Confessores humiles ut sint preces flebiles Deo acceptabiles nobis impetrate. Iesu parce ei.

26, Aubry, Pierre et Misset, E.: Les proses d'Adam de Saint Victor. (Paris: H. Welter, 1900).

27. Damilano, Piero: «Fonti musicali della lauda polifonica intorno alla metà del sec. XV», en Collectanea Historiae Musicae III (Firenze: Leo S. Olschki, 1963) pp. 59-90. 
5a. O sancte Dominice deprecantes respice ut cum summo iudice ista glorietur. Iesu parce ei.

6a. Caterina celica hanc de penis - Ihesu - pre - - a - am liberetur. Iesu parce ei. 5b. Chorus alme virginum exorate dominum ne pro culpis criminum tantum crucietur. Iesu parce ei.

6b. Omnis sancti ceteri aorent voce celeri ut a porta inferi ista reparetur Iesu parce ei.

7. Hanc absolve Domine a quocumque crimine ut in celis culmine gratis coronatur. Iesu parce ei. Iesu parce ei.

\section{III. «Versos» como tropos de Sanctus}

El Cantoral Pm califica como «versos» tres piezas dispuestas como tropos de Osanna escritas en los ff. 58v-61r. Los llamados «versos» se insertan dentro de la melodia gregoriana del Sanctus que en los tres casos ya ha aparecido anteriormente en el manuscrito y que está escrita en notación cuadrada no mensural, mientras que la pieza insertada se presenta en notación mensural. Las piezas tienen forma estrófica y en el caso de la primera y la tercera similar a una secuencia, pues la melodia se repite cada dos estrofas. La segunda de las piezas tiene la forma musical A ba A, siendo A un estribillo. En los tres casos se repite al final de cada estrofa una misma melodía. Estas dos características - estrofas y repeticiones melódicas al final de cada una de ellas - son en principio típicas de piezas de danza en lengua vulgar, como la ballata o el virelai, pero también se pueden relacionar con la lauda latina. ${ }^{28} \mathrm{La}$ lauda se interpretaba en Italia en hermandades y en el ambiente de algunas órdenes (franciscanos y dominicos sobre todo), pero también en contextos monásticos como demuestran fuentes como el laudario de Bobbio (I-To n F.I.4), con 13 laudas en latín que suponen la adaptación del popular género a las necesidades y costumbres monástica.

Ninguna de las rúbricas de Pm indica que estas piezas se bailaran y la relación con ambientes de laudesi y con Italia me parece lo más probable, pero se puede también proponer la sugerente hipótesis que estas piezas lo sean de danza. ${ }^{29}$ Una fuente catalana, de época cercana a Pm contiene varios ejemplos de piezas de danza en latín: el Llibre Vermell (E-MO 1), copiado

28. Sobre las obras latinas con empleo de formas típicas de canciones en lenguas vernáculas ver por ejemplo SPANKE, $\mathrm{H}$ : «Das lateinische Rondeau» en Zeitschrift für französische Sprache und Literatur LIII (1929), 113 y ss. y GENNRICH, F.: Grundriss einer Formenlehre des mittelalterlichen Liedes als Grundlage einer musikalischen Formenlehre des Liedes. (Halle, 1932).

29. El empleo de la danza en la liturgia es un tema tratado ya desde SpANKE, H.: «Tanzmusik in der Kirche des Mittelalters» en Neuphilologische Mitteilungen, 331 (1930), pp. 143-170). 
entre 1396 y 1399 contiene normas relativas a los peregrinos que venían al santuario de la Virgen de Montserrat y 10 cantos no relacionados directamente con la liturgia, de los cuales 5 son piezas de danza - tres con la forma «virelai»-y algunas con rúbricas al respecto («a bal redón», «ad tripudium rotundum»). Excepto una, en catalán, estas danzas están en latín.

Respecto a la peculiar colocación litúrgica de las piezas, no son desde luego las únicas canciones medievales que se cantaban como tropos dentro de la liturgia, ni las únicas danzas insertas como tropos. Estas inserciones se hacían sobre todo en las procesiones, pero también en las horas y en la misa. Ha sido estudiado, entre otros, el caso del manuscrito 464 de la Biblioteca de la Universidad de Erlangen (D-ERu 464), del siglo XV descrito por Rudolph Stephan en $1956^{30}$ que contiene en el f. $31 \mathrm{v}$ una conocida melodía de Sanctus señalada con un signo se repite ante los Osana y el Benedictus. Ante el primer signo escribe «Surrexit xps hodie lxxxiiii» y efectivamente en el f. 84 encontramos otro Sanctus con los mismos signos en el mismo lugar. Bajo este segundo Sanctus se encuentra el texto de una conocida canción pascual, Surrexit Christus hodie, tras cada una de cuyas estrofas se ha escrito una versión alemana del mismo texto. El manuscrito no tiene notación, pero las melodías de ambos Sanctus son conocidas y si se colocan los textos de la canción donde los signos parecen indicarlo, resulta una especie de tropo de Sanctus aplicado a dos melodías diferentes en distinto modo. En el f. 34 hay otro Sanctus sin texto en el que una mano ha escrito «Schwabacher Placz», en dialecto bávaro «danza de Schwabach» (ciudad cercana a Nürnberg). La danza está además escrita en notación de cantus fractus.

Sanctus. Hosanna. Gaudeat chorus celestium.

La melodía de este Sanctus ya ha aparecido anteriomente en el el propio manuscrito de Pm en el ordinario de la misa para las fiestas «doble maior» (f. 13r). Aparece en el catálogo de Thannabaur con la melodia $n^{\circ} 203$ mientras que el tropo Gaudeat chorus lleva el $n^{\circ} 79$ del mismo catálogo. Se trata de una melodía de larga tradición, el Sanctus II del Graduale Romanum, con la cual Thannabaur ha podido relacionar numerosos tropos, tanto del Sanctus como del Osanna, de los que a fuentes de procedencia española sólo corresponden tres: el que ahora nos ocupa, Sospitati dedit mundum (a 2v en E-Boc 1, f. 4r) ${ }^{31}$ y Maria mater egregia (en E- TORc 135, f. 17v). La única fuente en la que aparece según Thannabaur el tropo Gaudeat chorus celestium es E-Bc 911: Tropario Prosario siglo XV, f. 159r. En dicho manuscrito aparece una versión de este tropo de Sanctus con notación cuadrada gregoriana con ocasionales figuraciones de caracter mensural. La versión de Pm por su parte, está escrita en notación mensural con L, B, S y punctum divisionis que señalan un compás ternario. Las versiones melódicas de Bc 911 y Pm son muy similares, con pequeñas variantes ornamentales, y Bc 911 incluye dos estrofas - texto y música- más que Pm.

Musicalmente el tropo es una composición sencilla en modo I en la que la melodia de cada estrofa se repite para la siguiente, a modo de una secuencia. Sílábica, con algunos neumas

30. STEPHAN, Rudolph: «Lied, Tropus und Tanz im Mittelalter» en Zeitschrift für deutsches altertum und deutsches Literatur 1956/1957, pp. 147-162.

31. Barcelona: Biblioteca del Orfeó Català ms. 1: Tropario con polifonía, siglo XIV. 
de dos o tres notas y con frecuentes repeticiones melódicas cuyo esquema sería el siguiente: estrofas 1ab: A A B C // estrofas 2ab: D D' B C, de manera que el final de las estrofas repite la misma melodía, como en la obra precedente o en la que le sigue, pero esta vez sin estribillo. La obra está en modo I con la mayor parte de las cadencias sobre RE y dos cadencias secundarias sobre DO. Son característicos los saltos melódicos de octava y quinta descendente así como los pasos por grados de $4^{\mathrm{a}}$ y $5^{\mathrm{a}}$ (do-fa-do y re-la-re). El ámbito de la pieza es de $11^{\mathrm{a}}$ (A-d).

El tropo está estructurado como una prosa estrófica con dos pares de estrofas (tres en la versión de Bc 911) de cuatro versos de rima aabb, ccbb (ddbb). Este tipo de tropos es característico de las adiciones al Osanna. Estas características y el empleo de versos rítmicos regulares indican que es una composición tardía. Es de destacar la rima final de los dos últimos versos de todas las estrofas en «o», la vocal con la que comienza el Osanna en el que se inserta este tropo. El tema del texto es frecuente en los tropos de Sanctus, ${ }^{32}$ la conjunción entre lo terrestre y lo divino y la alabanza angélica.

El texto del tropo es inédito y es el que sigue según la versión de Pm a la que hemos añadido las dos estrofas que aparecen en Bc 911.

Pm, f. 58v: Sanctus. Osanna. Gaudeat chorus celestium.

Sanctus, sanctus, sanctus.

Dominus Deus sabaoth.

Pleni sunt caeli et terra gloria tua.

Osanna in excelsis.

Benedictus qui venit in nomine Domini.

1a. Gaudeat chorus celestium, gaudeat ordo terrestrium in trinitate et sacrificio ymnum cantent divino gaudio.

1b. Mater patris divinum filium concepisti concedo propium cum castitate nostri remedio conditorem non obstat racio.

2a. O genitrix tui genitura caeli plaudent stellequem natura nativitate ridet sol radio crescit luna nati dominio.

2b. Angelorum virgo mater pura sine viro fructum paritura humanitati celestis concio convalescit tuo nato pio. Osanna in excelsis. Bc 911 f. 159r:

(3a. Salve salus humani generis salva sanos roga pro miseris

32. Iversen, Gunilla: Corpus Troporum VII: Tropes de l'ordinaire de la messe. Tropes du Sanctus. (Stockholm: Alqvist \& Wiksell International, 1990), p. 41. 
inmediati nostri remedio protulisti sedentem solio.

3b. Roga patris a nobis moneris manda natum et mater diceris virginitate da ut iudicio qui escamus cum tuo filio. Osanna in excelsis.)

\section{Sanctus. Osanna. Verbum caro factum est.}

El segundo de los tropos de Sanctus se escribe con la melodía $n^{\circ} 49$ de Thannabaur, el Sanctus IV del Graduale Romanum, una conocida melodía de la que se conocen numerosos tropos (50 cita Thannabaur), muchos de ellos en fuentes españolas.

A pesar de que es una de las melodías de Sanctus más populares y empleadas para los tropos, en ningún caso se le conoce como tropo el texto del manuscrito Pm, una curiosa mezcla en la que convive la melodía litúrgica del Sanctus con una pieza de ritmo ternario y con la forma musical A ba A. Tras las tres estrofas, se retoma la melodía gregoriana en notación no mensural para entonar «In excelsis Deo».

La melodía del Sanctus, como en el caso anterior, ya ha aparecido en el mismo manuscrito, en el ordinario de la misa de los santos apóstoles (f. 15r), es una melodía de modo VIII que no tiene ninguna relación con el «tropo» que le sigue, de hecho, la melodía del tropo, en modo I, choca con el final en sol del Osanna y con el apéndice «in excelsis» que canta entre sol y re en modo VIII. Destacamos que en Pm se mantiene el SI de la entonación que no a ascendido al DO como en la mayoría de las versiones.

Verbum caro no es un tropo de Sanctus, sino una canción latina con forma textual AB $\operatorname{cccB} \mathrm{AB}$ intercalada dentro de la liturgia de la misa y sin relación ninguna con la melodía gregoriana. El texto de esta pieza procede de un conductus monódico de tema navideño que aparece como fuente más antigua en F-Pn 1139, f. 48r, incluyendo el refrán De virgine Maria. In hoc anni circulo y Fons de suo rivulo las dos primeras estrofas de la pieza de Pm son a su vez las dos primeras estrofas de este conductus. La tercera estrofa, Dominus pro famulo no está en F-Pn 1139 ni en las otras fuentes consultadas. La obra tuvo gran éxito en la Edad Media y se conocen múltiples versiones de la misma, tanto en monodía como en polifonía, ${ }^{33}$ contrafacta en italiano ${ }^{34}$ y versiones como lauda latina en Italia con este y otros textos. ${ }^{35}$

33. Hughes, Anselm: «In hoc anni circulo» The Musical Quarterly, LX, n. 1 (1974), pp. 37-45 indica el origen del estribillo de esta pieza y comenta algunas de esas versiones.

34. DüRRER, Martin: Altitalienischen Laudenmelodien. Das einstimmige Repertoire der Handschriften Cortona und Florenz. 2. Bände (Kassel: Bärenreiter, 1996) p. 30: (en el manuscrito Siena, Bib. Chigiana L.VII.266, s. XV, se lee en la lauda «Mosso da sancta pazzia / vo narrar la vita mia»): ...cantasi come «Senno mi pare e cortezie» $e$ «Verbum caro». Offenbar auf die gleiche Melodie zu singen sind auch «Faccian festa e giulleria / che é nato il buon messia» (cantasi come «Senno mi pare») und «Salve Virgo pretiosa» (in sù: «Senno mi pare»).

35. Damilano, Piero: «Laudi latine in un Antifonario bobbiese del Trecento», en Collectanea Historiae Musicae III (Firenze: Leo S. Olschki, 1963) pp. 15-57: en el manuscrito I-Tn F.I.4 (mediados s. XIV) aparece la lauda latina Verbum caro, y con la misma melodía, la lauda Hodie lux orta est. 
De las varias versiones conocidas la melodía Pm concuerda por lo que he podido comprobar con la de I-Tn F.I.4, antifonario de mediados del siglo XIV procedente de la abadía benedictina de Bobbio que contiene en su último fascículo 13 laudas latinas entre las cuales ésta. En la obra citada de Damilano se edita tanto el texto como la música del laudario de Bobbio, pues, como éste autor indica, en AH 20, p. 22 se cita este texto -referido a To n F I.4- pero no se edita.

Así pues, la versión más antigua que he localizado de esta melodía procede del norte de Italia y emplea el mismo texto - con más estrofas - que el manuscrito de Palma. La popularidad de la pieza, su antiguo origen y su gran difusión no permiten afirmar que el origen de esta melodía sea italiano, no obstante, ésta es la melodía en la que se basa Pm para realizar una versión más adornada y en un estilo rítmico más moderno.

No edito el texto de esta pieza y la que sigue porque puede leerse entero en la transcripción que aparece al final de este artículo.

\section{Sanctus. Osanna. Ave verum corpus natum.}

El Sanctus, como los anteriores, ya ha aparecido en el manuscrito para las «fiestas de doble mayor» (f. 17r). Su melodia es la $\mathrm{n}^{\circ} 116$ de Thannabaur -Sanctus VIII del Graduale Romanum - y que aparece en este catálogo con un tropo que tiene este mismo incipit y procedede $\mathrm{Bc}$ 911. El texto de Pm está editado como secuencia en AH 54, n 167 (con una ligera adición de la palabra «Ihesu» en Pm para el último verso) y también en AH 37 nº 37 en una versión más amplia.

Si bien esta pieza era originalmente una secuencia, parece haber tenido una amplia tradición como canción latina en la que se han suprimido algunos de sus versos y se ha eliminado la duplicación de la última estrofa. En ninguna de las fuentes que cita $\mathrm{AH}$ se menciona ninguna relación de esta pieza con un Sanctus, se considera en las rúbricas oración «ad hostiam», «plegaria», «secuencia» o «cantio» (AH 54 p. 258). El texto se hizo popular en la Edad Media también como lauda.

Ave verum tiene otra concordancia en la fuente E-Bc 911, f. 161r, con el mismo Sanctus y el mismo tipo de inserción de la pieza dentro de éste y en Bc 1327 f. 169v, pero en estas dos fuentes, que llevan ambas la misma melodía basada en la del Sanctus, tampoco se emplea la melodía de Pm. Parte de este texto (hasta «examine») aparece en fuentes con laude latinas polifónicas: I-Bu 2216 f. $23 r^{36}$ (escrito entre 1430-1440) a tres voces, e I-Mo 871, f. $408 \mathrm{r},{ }^{37}$ también a tres voces. En ninguno de los dos casos su melodía concuerda ni con Pm ni con la de las otras fuentes españolas. Respecto a la estructura musical, es también una pieza con repeticiones musicales en el final de cada estrofa, aunque la estrofa 3, tiene una melodía diferente: estrofas 1ab: A B, estrofas $2 \mathrm{ab}$ : C B. Como el resto de las piezas está escrita en modo I, con importancia de la nota MI para las cadencias secundarias y un ámbito de $9^{\mathrm{a}}$.

36. Bologna: Biblioteca Universitaria ms. 2216.

37. Montecasino, Ms. 871, siglo XV. 
Muchas interesantes cuestiones se plantean con el estudio de este cantoral. La tradición trópica y las melodías de los Credo de las monjas de Palma de Mallorca aproximan este manuscrito a fuentes contemporáneas de origen italiano. Por otra parte las piezas inéditas presentan una serie de características comunes entre sí que hacen pensar en una posible composición insular, o al menos en una tradición transmitida como conjunto a este monasterio agustino. El estudio de las relaciones entre las agustinas de Palma y otros monasterios italianos podría arrojar nueva luz sobre estos temas, así como, sobre todo, el estudio del resto de las fuentes musicales contemporáneas de la isla, portadoras de un rico e interesante repertorio aún sin estudiar. ${ }^{38}$

38. Este artículo ha sido realizado durante mi estancia en el Institut für Musikwissenschaft de la Universidad de ErlangenNürnberg gracias a una beca de la Fundación Alexander von Humboldt. Quiero manifestar un emocionado recuerdo para el Prof. Dr. Fritz Reckow, director de dicho Institut, prematuramente fallecido en agosto de este año de 1998 y mi agradecimiento a todo el personal del Institut y Bruno Stäblein Archiv, especialmente a la Dra. Raffaella Camilot-Oswald, por toda la ayuda que me han prestado. 
Pm, f. 40v: Prosa para la fiesta de los Stos. Apóstoles S. Pedro y S. Pablo.

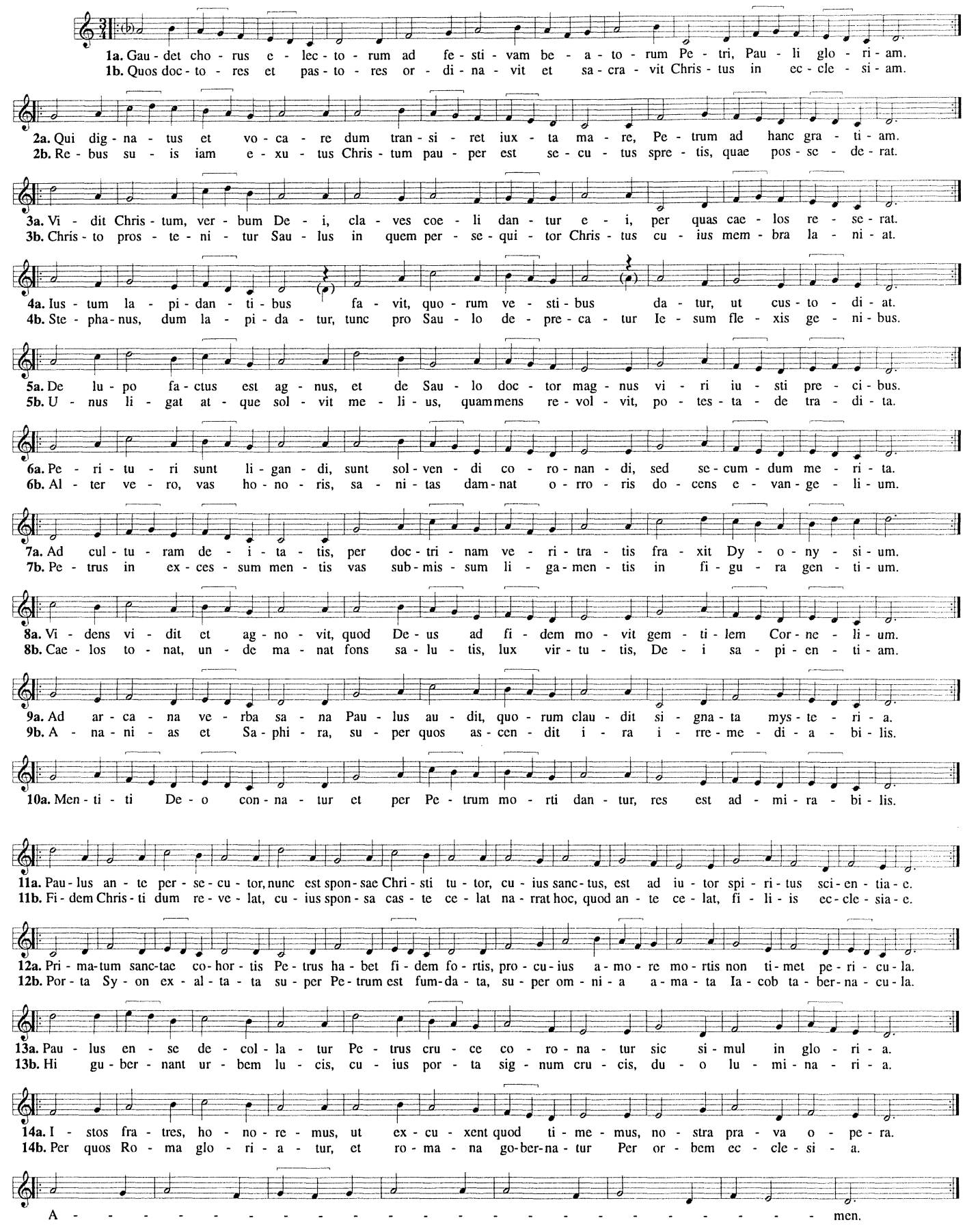


Pm, f. 44v: Verbeta (Prosula) para la fiesta de la Circuncisión.

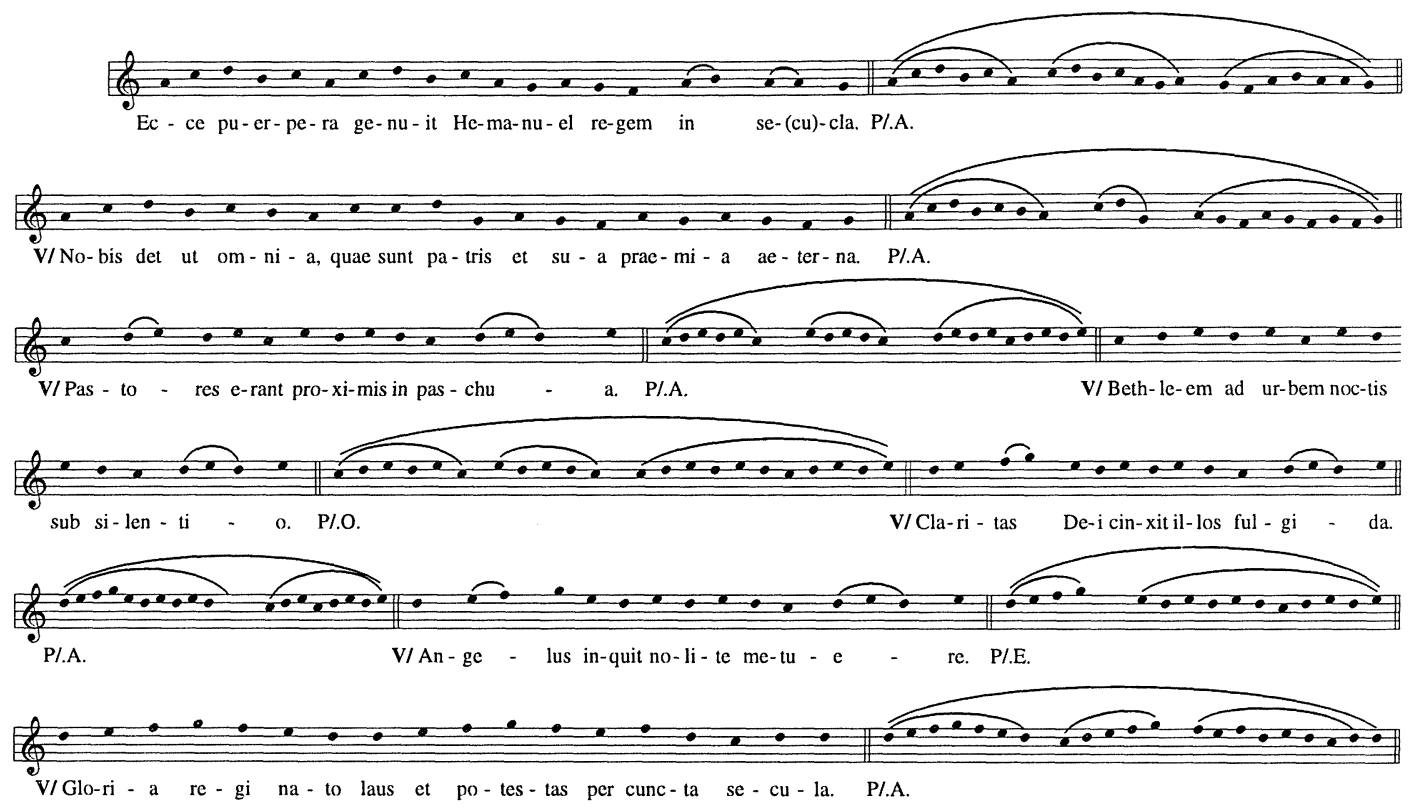


Pm, f. 45v: Verbeta (Prosula) para la fiesta de San Juan Bautista.

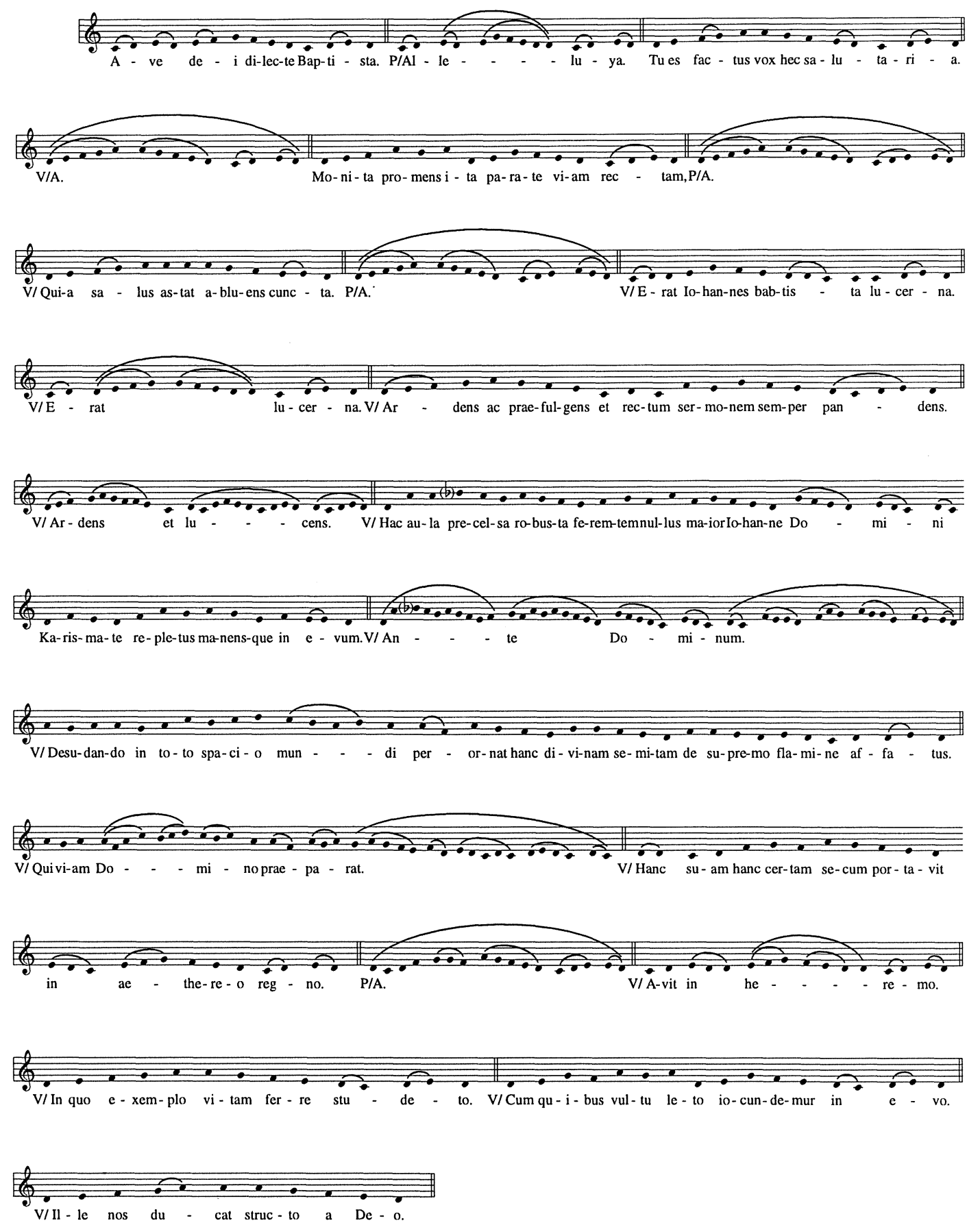


Pm, f. 47v: Verbeta (Prosula) para la fiesta de la Ascensión.

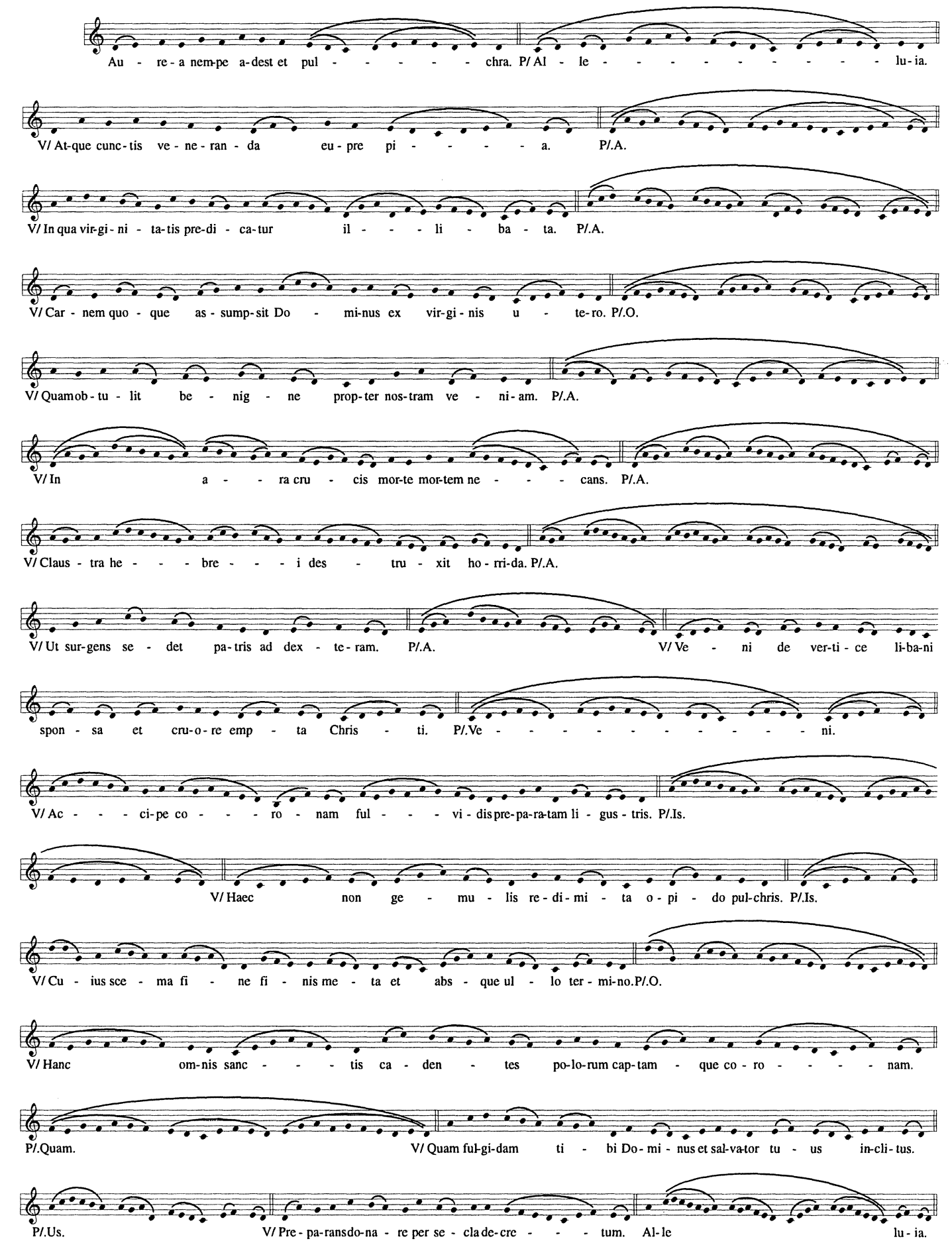

Anuario Musical, 53 (1998) 
Pm, f. 49r: Prosa ante el cuerpo presente de una hermana difunta.

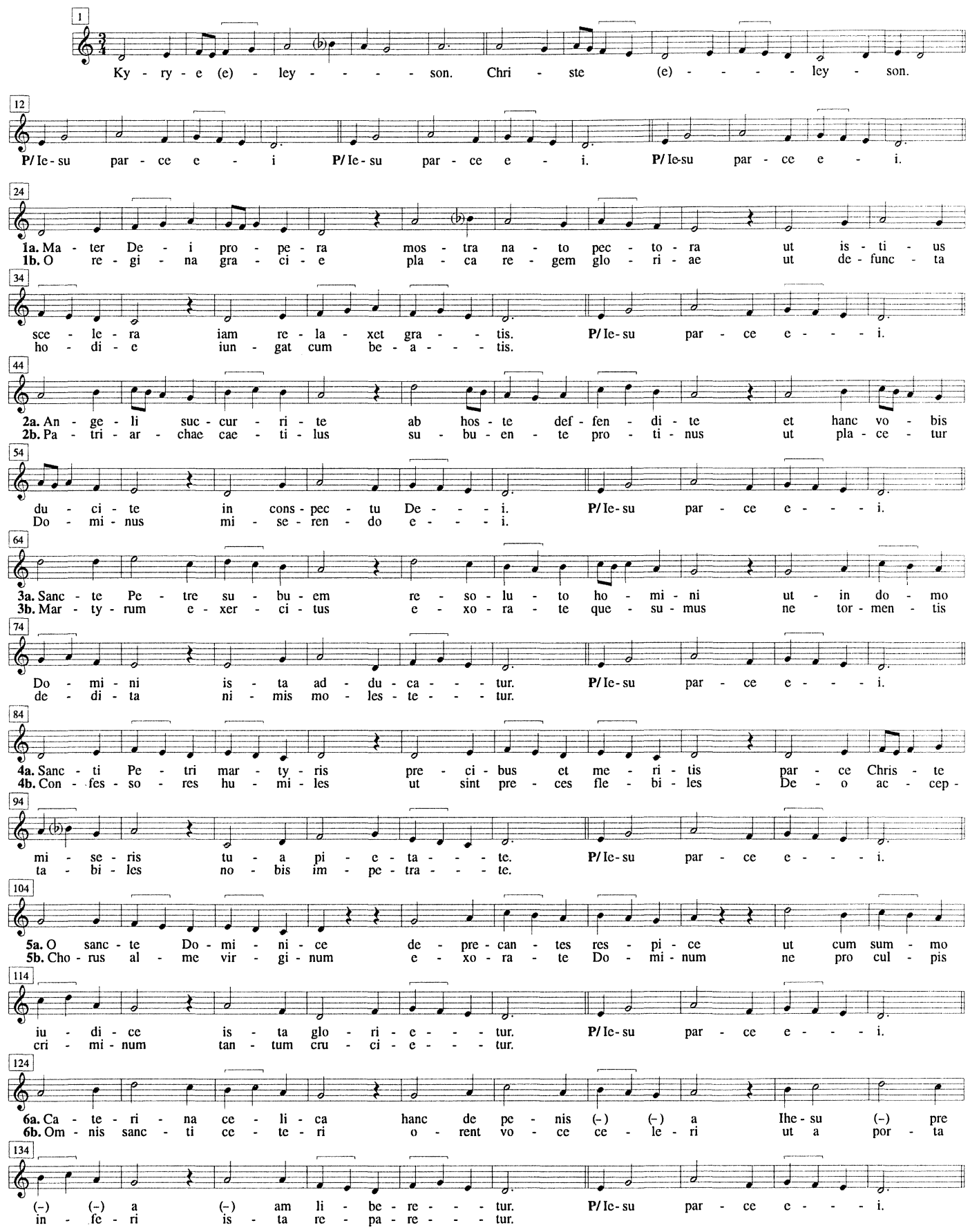




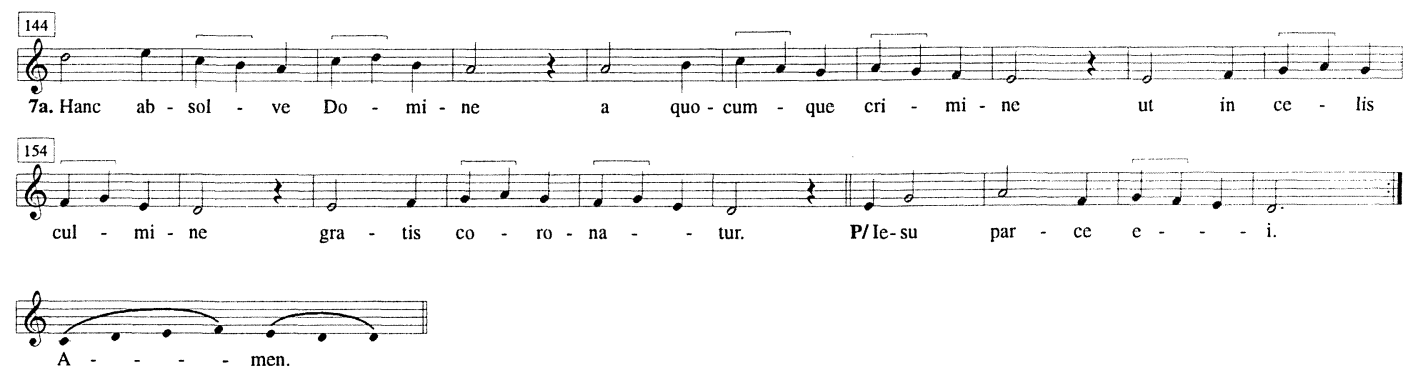

Pm, f. 58v: Sanctus. Osanna.Gaudeat chorus celestium.
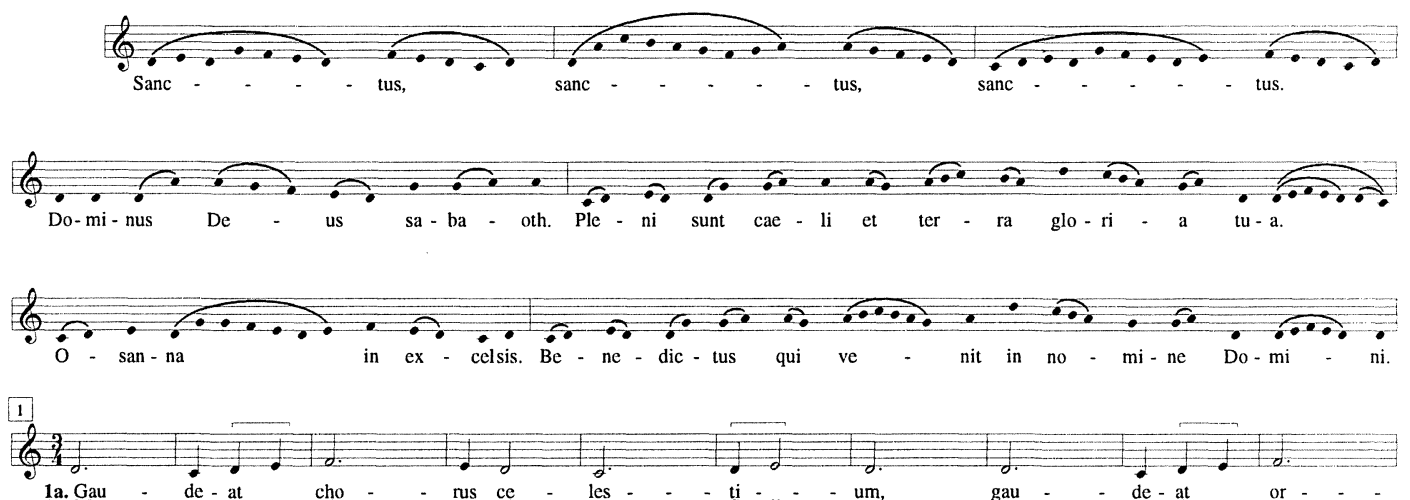

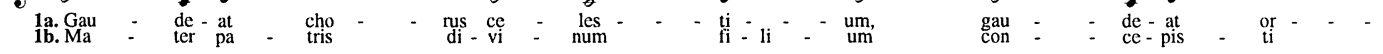
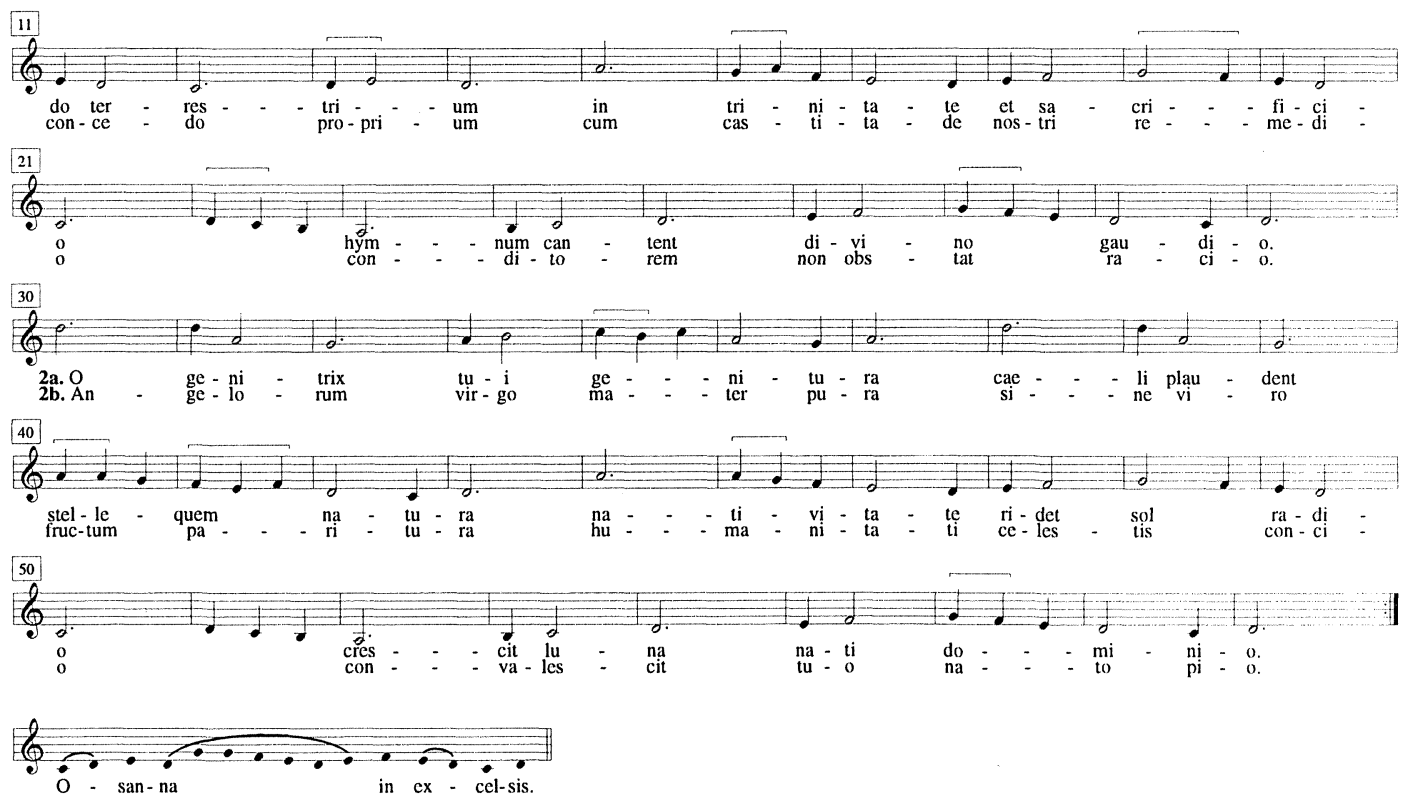
Pm, f. 59v: Sanctus. Osanna. Verbum caro factus est.

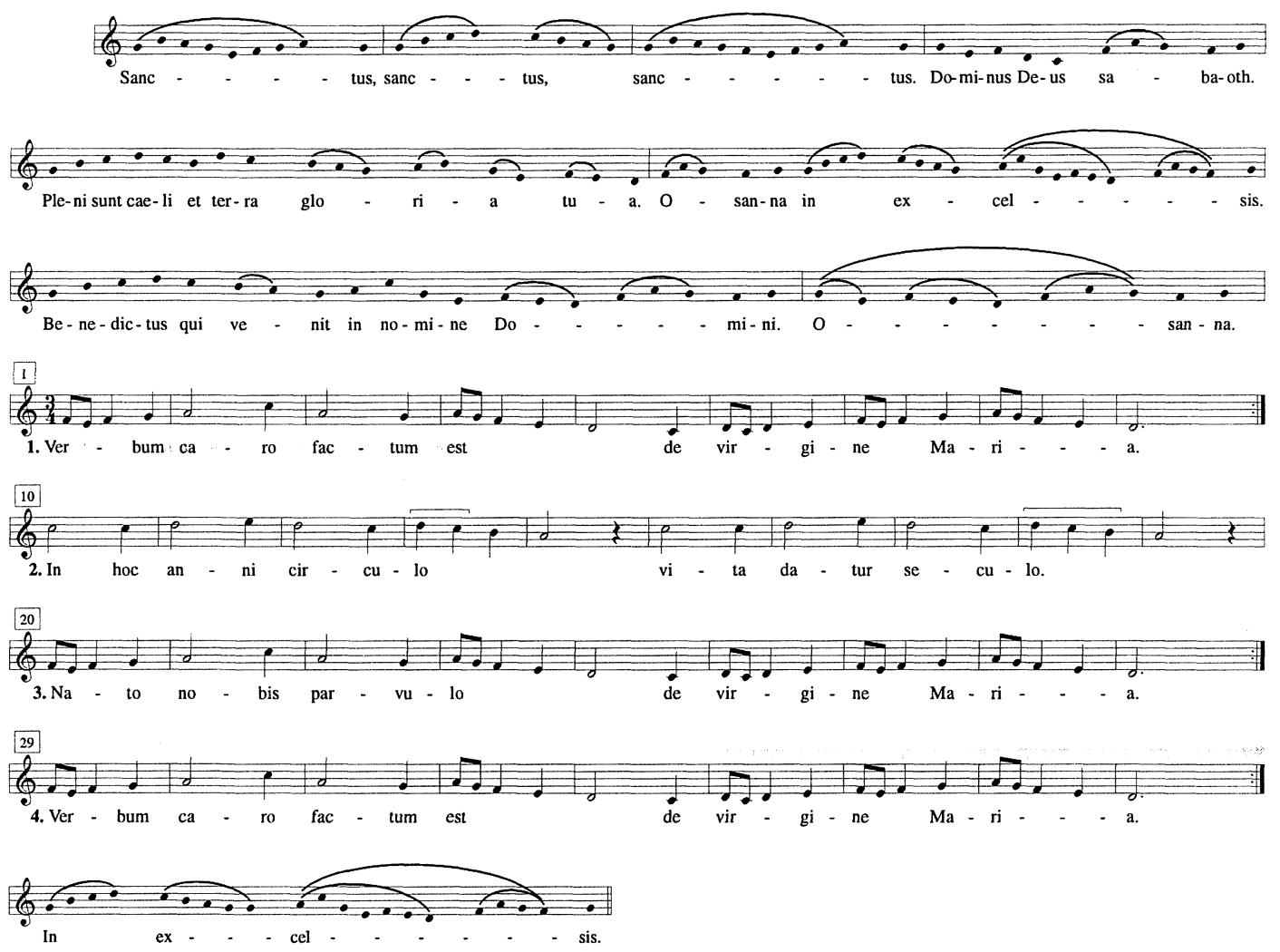

2. Fons de suo rivulo oritur pro populo

De sub mortis vinculo de virgine Maria.

Verbum caro factum est de virgine Maria.

3. Dominus pro famulo nasci vult diluculo Et pauper in stabulo de virgine Maria.

Verbum caro factum est de virgine Maria.

Verbum caro factum est de virgine Maria. In excelsis. 
Pm, f. 60v: Sanctus. Osanna. Ave verum corpus natum.

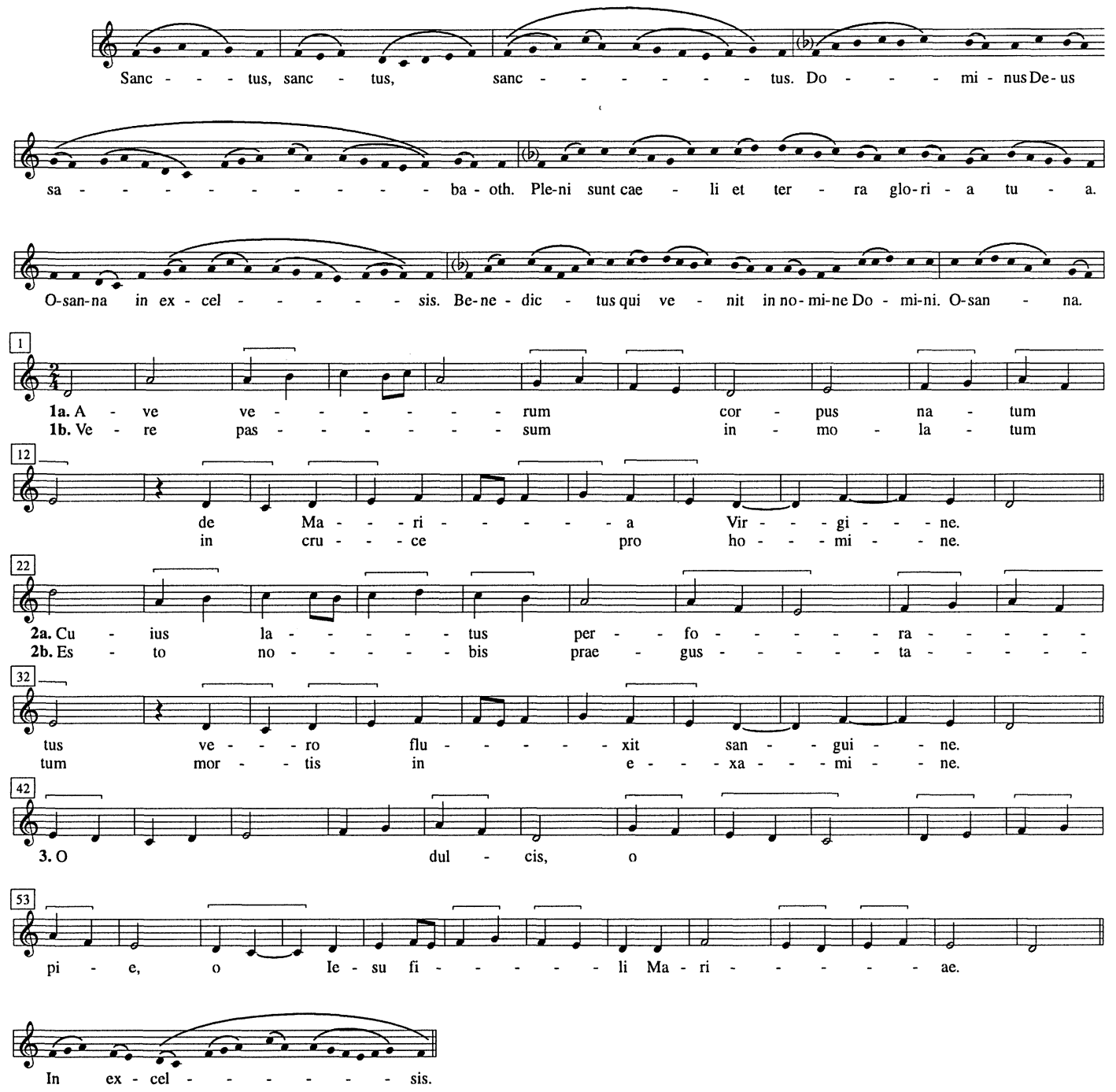



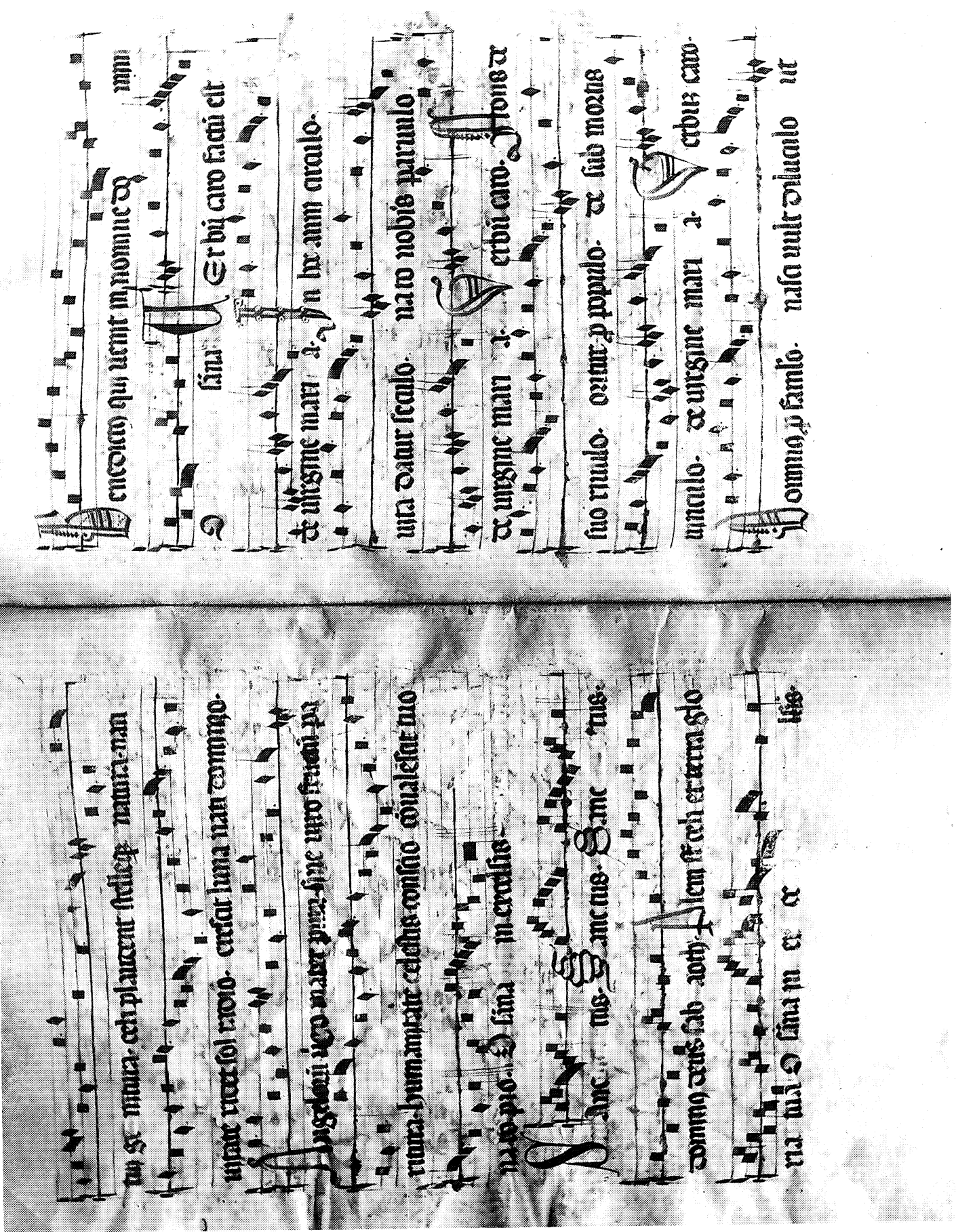

Cantoral de la Concepción

Palma de Mallerca, Museo Diocesano, s/n. fol. 59v.-60v. 